\title{
O SIGNIFICADO PALEOGEOGRÁFICO DAS TURFEIRAS COSTEIRAS DO RIO GRANDE DO SUL
}

\author{
THE PALEOGEOGRAPHIC MEANING OF THE COASTAL PEATS OF RIO GRANDE DO SUL \\ Leonardo Gonçalves de LIMA, Sérgio DILLENBURG², Francisco BUCHMANN³, \\ Cláudia PARISE ${ }^{1}$ \\ ${ }^{1}$ Universidade Federal do Maranhão - UFMA, Departamento de Oceanografia e Limnologia. Avenida dos Portugueses, 1966 - Vila \\ Bacanga, São Luís - MA. E-mail: paleonardo_7@ hotmail.com; claudiakparise@gmail.com \\ ${ }^{2}$ Universidade Federal do Rio Grande do Sul - UFRGS. Avenida Paulo Gama, 110. Porto Alegre - RS. \\ E-mail: sergio.dillenburg@ufrgs.br \\ ${ }^{3}$ Universidade Estadual Paulista - UNESP. Praça Infante D. Henrique s/n, São Vicente SP. E-mail: paleonchico@ yahoo.com.br
}

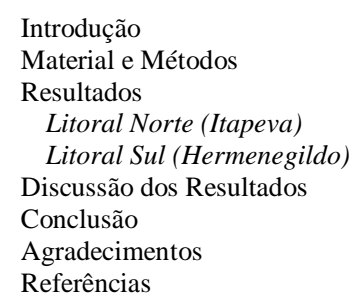

RESUMO - Na Planície Costeira do Rio Grande do Sul (PCRGS) depósitos de turfas afloram ao longo do litoral indicando os setores onde as barreiras costeiras exibem uma natureza transgressiva. Ao longo das últimas décadas várias causas foram apontadas para explicar o processo erosivo nestes setores, todas associadas a fenômenos naturais. Estas turfas aflorantes são tidas como elemento chave no entendimento da evolução costeira de longo termo deste litoral. O processamento químico das amostras foi realizado a frio com $\mathrm{HCl}(5 \%)$ e $\mathrm{KOH}(5 \%)$ e separação entre partículas orgânicas e inorgânicas com solução aquosa de $\mathrm{ZnCl}_{2}$. Este estudo se baseou em amostras de turfas obtidas de sondagens geológicas, afloramentos e perfilagens com Georradar nas praias de Itapeva e Hermenegildo. Os resultados indicam que o estrato basal que recobre os sedimentos pleistocênicos é formado por turfas, sinalizando cronologicamente o início da sedimentação holocênica na PCRGS em torno de 10.000 anos AP, quando ainda prevaleciam condições essencialmente lacustres, nas posições que viriam a se desenvolver os sistemas de barreiras costeiras holocênicas. Uma vez instaladas, estas barreiras criaram condições para o desenvolvimento de uma segunda geração de ambientes paludiais, desta vez, vinculados à redução das profundidades dos sistemas lagunares em processo de colmatação, por volta de 710 anos AP. Este estudo fornece evidências de que a linha de costa atual da PCRGS encontra-se num processo contínuo de reorientação, conduzido por um déficit sedimentar nos setores costeiros onde as barreiras retrogradantes migram para o continente e no sentido N-NO, expondo depósitos turfáceos sistematicamente ao longo do litoral.

Palavras Chave: Turfa, Paleogeografia, Planície Costeira

\begin{abstract}
In the Coastal Plain of Rio Grande do Sul (PCRGS), peat deposits appear along the coast indicating sectors where coastal barriers exhibit a transgressive nature. Throughout the last decades, many causes are composed to explain the erosive process in these sectors, major associated with natural phenomena. These outcrops are considered as key elements in the understanding of the long term evolution of this coast. The chemical processing of the samples was made in cold mode with $\mathrm{HCl}(5 \%)$ and $\mathrm{KOH}(5 \%)$ and the separation of organic and inorganic particles with aqueous solution of $\mathrm{ZnCl}_{2}$.This study was based on peat samplings from geological surveys, outcrops and Georadar profiles in the beaches of Itapeva and Hermenegildo. The results of this study indicate that the basal layer covering the pleistocene sediments is formed by basal peat, chronologically signaling the beginning of Holocene sedimentation in the PCRGS around 10.000 years BP, when still essentially lacustrine conditions prevailed through the dominance of herbaceous and hydrophitic vegetation where the Holocene coastal barrier systems would develop. Once installed, these barriers created the conditions for the development of a second generation of paludal environments, this time linked to the reduction of the environmental depths during the process of filling since 710 years B.P. The results of the present study provide evidences that the current coastline of the Rio Grande do Sul is in a continuous process of reorientation, led by a sedimentary deficit in the coastal sectors where the retrograde barriers migrate towards the mainland and to the N-NO direction, exposing peat deposits systematically along the coast.
\end{abstract}

Keywords: Peat, Paleogeography, Coastal Plain.

\section{INTRODUÇÃO}

No litoral central do Rio Grande do Sul (RS), nas proximidades do Farol da Conceição e no litoral sul, na praia do Hermenegildo, afloram amplos depósitos turfáceos no pós-praia e estirâncio (Figuras 1 e 2). A continuidade lateral das turfas expostas pode ser mapeada por uma

distância em torno de $100 \mathrm{~km}$, revelando a expressiva dimensão destas antigas turfeiras (Tomazelli et al. 1999). Estes depósitos são indicativos que estas localidades se encontram submetidas a processos erosivos de longo período, condicionados por um balanço negativo de 
sedimentos no sistema costeiro (Tomazelli \& Villvock, 2000; Lima et al., 2013). Nestes setores, as barreiras estreitam-se progressivamente de norte a sul e ilustram uma tendência de retração da linha de costa associada a uma significante migração das barreiras costeiras em direção ao continente, com campos de dunas transgressivos avançando sobre os ambientes paludais de retrobarreira (Buchmann et al., 1998; Lima et al., 2013). Na Planície Costeira do Rio Grande do Sul, o estabelecimento de ambientes paludais encontra-se sujeito a uma rápida evolução geomorfológica proporcionada pela migração de zonas ecológicas sob a influência das transgressões e regressões marinhas.

A origem dos sistemas de barreiras costeiras modernas (holocênicas) foi decorrente da elevação do nível do mar por ocasião da Transgressão Marinha Pós-Glacial (Field \& Duane, 1974; Swift, 1976; Swift \& Thorne, 1991; Roy et al., 1994; Cowell et al., 1999). Na costa do RS, o desenvolvimento das barreiras holocênicas esteve sempre acompanhado de amplos depósitos lagunares (lamas) e paludais (turfas) que afloram na linha de costa atual bem como na plataforma continental, indicando o caráter transgressivo da linha de costa (Tomazelli \& Dillenburg, 1989; Martins \& Martins, 2004; Corrêa et al., 2015). Várias causas foram apontadas para explicar a natureza do processo erosivo nestes setores, todas associadas a fenômenos naturais: (1) elevação atual do nível relativo do mar (Tomazelli \& Villwock, 1989; Tomazelli, 1990; Tomazelli et al., 1998); (2) efeito das marés meteorológicas associadas a eventos de tempestades (Calliari et al., 1996); (3) concentração de energia de ondas devido à refração em feições morfológicas submersas (Calliari \& Pereira da Silva, 1998) e (4) concentração de energia de ondas controlada por feições morfológicas de grande escala, associadas à topografia antecedente à última grande transgressão (Dillenburg et al., 2000). Segundo Tomazelli et al. (1999) as causas apontadas não são excludentes e é provável que o fenômeno erosivo resulte da superposição das mesmas. Uma revisão crítica sobre as causas da erosão costeira no RS foi apresentada por Dillenburg et al. (2004), onde foram confrontadas abordagens em distintas escalas (curto e longo prazo) deste processo.

Turfeiras são formadas em um substrato pedológico que se desenvolve em condições de encharcamento, anóxia e baixo pH (Evans \& Warburton, 2007). São ecossistemas em que o nível da água se encontra na superfície ou perto desta e em que o encharcamento é suficientemente prolongado para promover processos típicos de solos mal drenados como o desenvolvimento de vegetação hidrofítica onde ocorre a formação da turfa. Estas condições, permitem a humificação e mineralização da matéria orgânica bem como a preservação continuada das estruturas biológicas presentes nestes ambientes deposicionais. Interpretações paleoambientais, variações no clima e na vegetação para o Holoceno Médio e Tardio consideram sobretudo as variações de precipitação e tem por base de evidência a paleohidrologia de turfeiras (Behling, 1995; Gouveia et al., 1997; Victoria et al., 1995).

Ambientes deposicionais paludais e lagunares são elementos chave no entendimento de transgressões e regressões marinhas (Traverse \& Ginsburg, 1967; Kraft, 1971; Kraft \& John, 1979; Belknap \& Kraft, 1985; Martin et al., 1986; Domingues, 1987; Hunt, 1987; Gregory \& Hart, 1992). Devido a ampla preservação da matéria orgânica carbonosa e de pólen, as turfas permitem reconstituir precisamente a evolução das associações vegetais e determinar cronologicamente as diversas fases dessa evolução.

No Rio Grande do Sul estudos palinológicos têm contribuído para a consolidação do modelo evolutivo do chamado Sistema Lagunar IV (sensu Villwock, 1984), entre eles os trabalhos de: Cordeiro \& Lorscheitter (1994); Neves \& Lorscheitter (1995, 1996); Lorscheitter \& Dillenburg (1998); Neves (1998); Medeanic et al. (2000, 2001); Neves \& Bauermann (2001); Marques-Toigo et al. (2002); Bauermann, (2003); Medeanic (2006); Lima (2008) e Lima et al. (2013).

Como as turfeiras são indicadores de mudanças ambientais, podem ser utilizadas na reconstrução paleoambiental e paleogeográfica de maneira muito precisa, principalmente pelo abundante registro paleontológico/estratigráfico, uma vez que são preservados paleoníveis freáticos com relação ao topo destas acumulações. Da mesma forma, a base e as margens destes sistemas podem indicar de que forma estes ambientes ocupam a topografia/geologia antecedente estabelecendo um registro fiel da paleogeografia de turfeiras desde o ótimo climático do Holoceno até os dias 
atuais (Kraft, 1971). Nesse sentido, o objetivo desse trabalho é discutir a gênese dos ambientes paludais na Planície Costeira do Rio Grande do
Sul de forma a identificar as mudanças paleoambientais holocênicas na evolução de sistemas de barreiras costeiras.

\section{MATERIAL E MÉTODOS}

O presente estudo desenvolveu-se com base numa revisão e reinterpretação dos trabalhos de Lima (2008) e Lima (2012) nos quais foram realizadas amostragens de sub-superfície e observações geomorfológicas de superfície. Nas etapas de prospecção de campo, foram percorridos, entre os anos de 2002 e 2012, um total de $1.500 \mathrm{~km}$ envolvendo terrenos quaternários, entre os limites dos sistemas de barreiras costeiras no Rio Grande do Sul (Figura 1). Em soma às prospecções de campo, foram realizadas compilações de documentos cartográficos, fotográficos e produtos de sensoriamento remoto (imagens de satélite e fotos aéreas), e realizados levantamentos topográficos utilizando Estação Total e DGPS, amostragens sedimentológicas de superfície, descrição de afloramentos (Figura 2) e levantamentos botânicos.

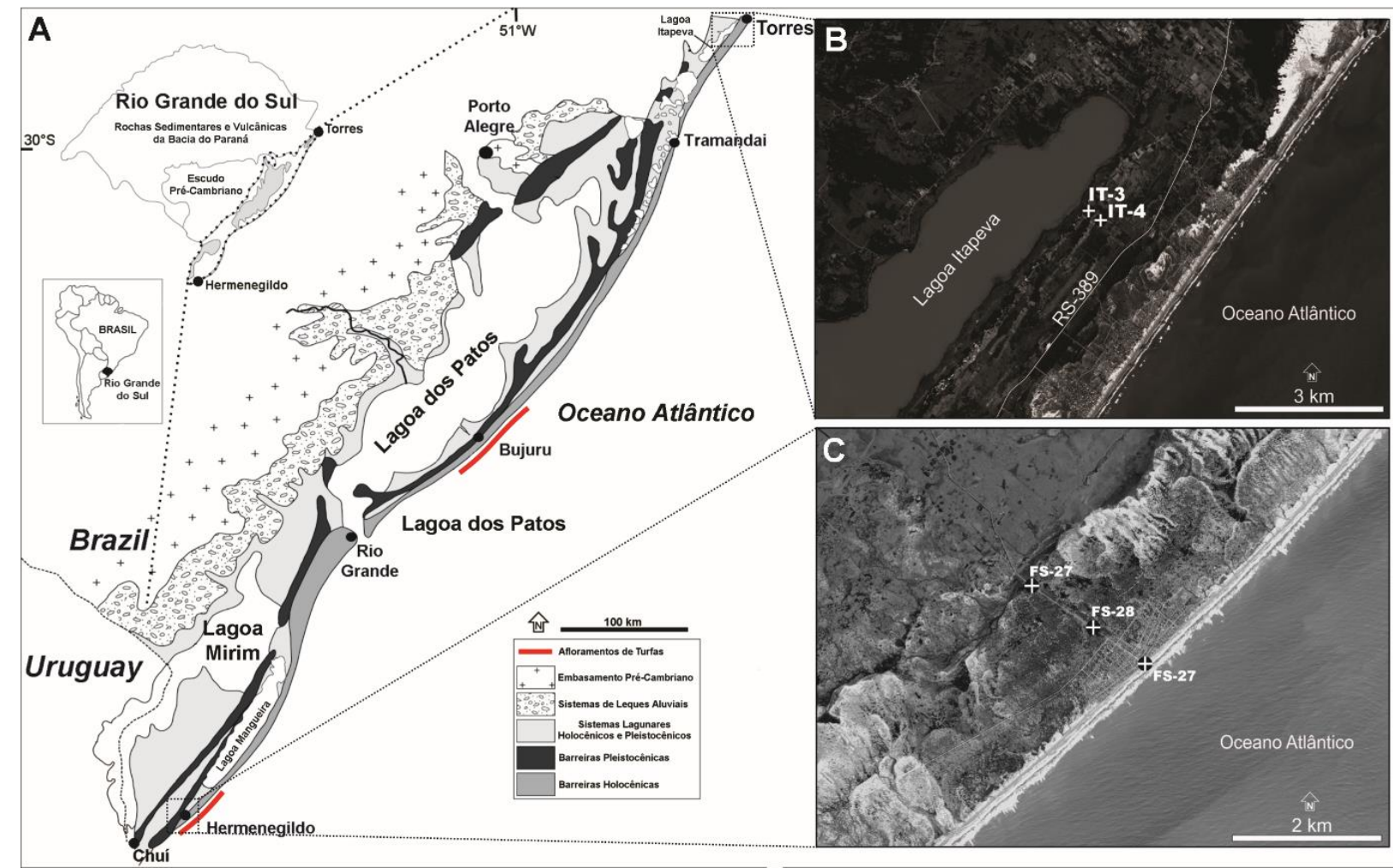

Figura 1 - Mapa de localização. A) Mapa de localização indicando a localização dos afloramentos turfáceos na atual linha de costa; B) Localização das sondagens executadas na localidade da Lagoa Itapeva. C) Localização das sondagens executadas na praia do Hermenegildo.

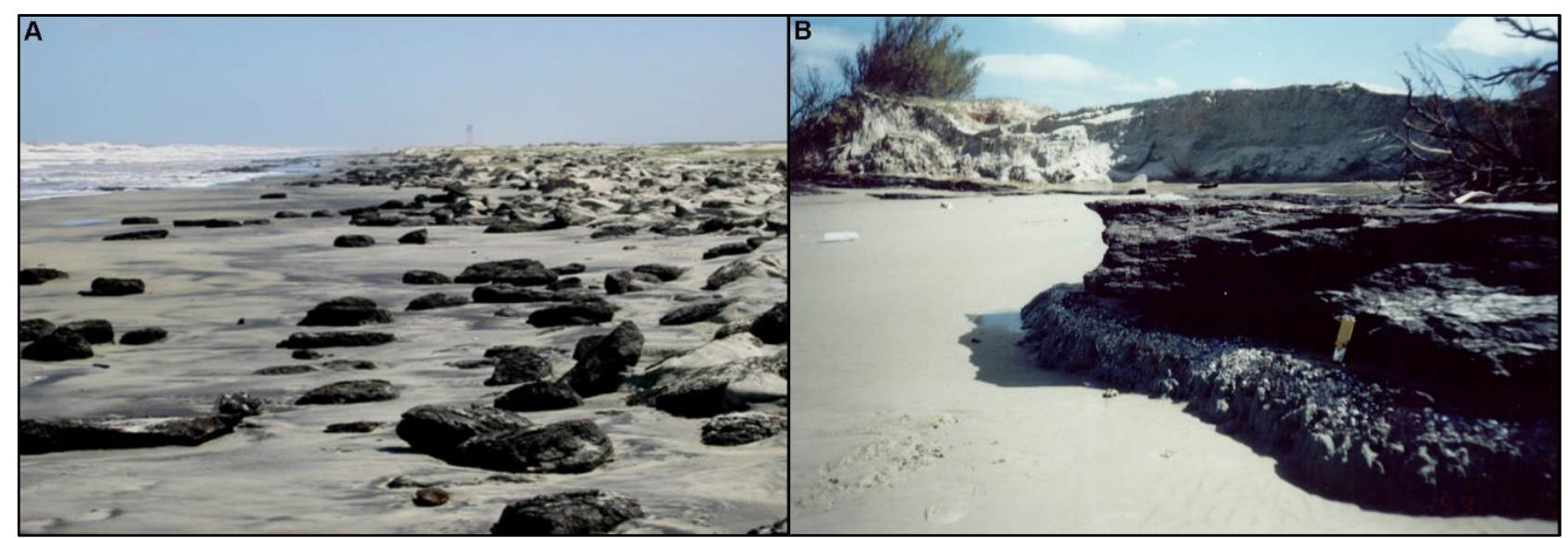

Figura 2 - Afloramento de turfas na linha de costa. A) Afloramento de turfas no estirâncio de Bojuru, nas imediações da Lagoa do Peixe (retirado de Arejano, 2006). B) Afloramento de turfas no estirâncio ao sul da Praia Hermenegildo (retirado de Buchmann, 1997).

São Paulo, UNESP, Geociências, v. 39, n. 2, p. 393 - 410, 2020 
Os resultados de GPR obtidos por Lima et al. (2013) definiram o posicionamento de sondagens Standard Penetration Test (SPT) a qual é regulamentada no Brasil pela normativa NBR6468 da ABNT/CB (Associação Brasileira de Normas Técnicas/Comitê Brasileiro de Construção Civil) consistindo basicamente em uma medida de resistência dinâmica, conjugada a uma sondagem de reconhecimento. Essa técnica permite acessar grandes profundidades, porém, de forma descontínua. Isto é, a cada metro sondado obtém-se a recuperação de $45 \mathrm{~cm}$ de registro sedimentar intacto (não perturbado) e $55 \mathrm{~cm}$ de registro sedimentar perturbado (amostra de calha). A extração das amostras intactas $(45 \mathrm{~cm})$ é realizada à percussão de um peso batente $(65 \mathrm{~kg})$ incidindo sobre hastes de penetração conectadas ao amostrador do tipo RAYMOND/TERZAGHI. A penetração deste amostrador fornece um índice $\left(\mathrm{n}^{\circ}\right.$ golpes/penetração do amostrador) de compactação do depósito sedimentar. A extração das amostras perturbadas $(55 \mathrm{~cm})$ é realizada por meio da perfuração manual com um trépano auxiliado de circulação de água com bentonita.

A partir do registro sedimentar recuperado das sondagens foram coletadas alíquotas de $1 \mathrm{~cm}^{3}$ a cada $20 \mathrm{~cm}$ de registro, resultando em 15 amostras para análise de palinomorfos, diatomáceas e fitólitos. Estes últimos foram classificados segundo Lu e Liu (2003). O processamento químico das amostras seguiu as técnicas palinológicas descritas em Faegri \& Iversen (1975), adaptando-se o tratamento a frio com $\mathrm{HCl}(5 \%)$ e $\mathrm{KOH}(5 \%)$. O método de separação entre partículas inorgânicas e orgânicas ocorreu mediante a utilização de solução aquosa de $\mathrm{ZnCl}_{2}$ de densidade $2,2 \mathrm{~g} / \mathrm{cm}^{3}$.

As análises composicionais das amostras sedimentares incluíram a análise granulométrica (alíquotas de $2 \mathrm{~g}$ ) através de um analisador de partículas a laser CILAS (modelo 1180). As classes texturais foram individualizadas em 100 intervalos granulométricos definidos pelos limites de detecção dos sensores do analisador de partículas. O tratamento estatístico das amostras seguiu as técnicas descritas em Folk \& Ward (1957). Outra análise composicional empregada foi a morfoscopia dos grãos tamanho areia fina. Para a esfericidade adotou-se a classificação de Rittenhouse (1943), para o arredondamento a classificação de Krumbein (1941) e a textura superficial segundo a classificação de Bigarella (1955).

O carbono total de 6 níveis sedimentares (alíquotas de $5 \mathrm{~g}$ ) foi avaliado mediante a queima em um forno de Lavoisier durante 4 horas em temperatura de $550^{\circ} \mathrm{C}$, segundo método empregado por Wetzel (1975).

Análises de ${ }^{14} \mathrm{C}$ segundo o método (AMS) Accelerator Mass Spectrometry, num total de 3 amostras de sedimentos orgânicos em turfeiras foram realizadas no laboratório BETA ANALYTICS RADIOCARBON DATING LABORATORY em Miami, Flórida, EUA. Para a calibração das amostras utilizou-se da base de dados MARINE04 (Hughem et al., 2004) e INTCAL04 (Reimer et al., 2004) interpolados segundo o ajuste ponderado de spline cúbico descrito em Talma \& Vogel (1993).

\section{RESULTADOS}

\section{Litoral Norte (Itapeva)}

As turfeiras costeiras analisadas no presente estudo foram amostradas em sondagens geológicas e afloramentos, realizadas na praia de Itapeva (litoral norte do RS) e praia do Hermenegildo (litoral sul do RS) (Figura 1).

$\mathrm{Na}$ localidade da praia de Itapeva foram empreendidas duas sondagens geológicas designadas IT-3 e IT-4 (Figura 1). Ambas sondagens interceptaram um horizonte turfáceo/carbonoso (fácies TB1 - pântanos basais) nos registros mais basais das sondagens a -15 m do Nível Relativo do Mar (NRM) e com 2 $m$ de espessura (Figura 3). A base desta fácies na sondagem IT-3 é essencialmente arenosa gradando para lamosa (18\% silte) junto ao topo onde se verifica a presença de lentes de lama, cinza escuro (5GY4/1).

Esta amostra foi classificada de bem a moderadamente selecionada e muito compacta. Grãos tamanho areia fina ocorrem predominantemente arredondados (63\%), boa esfericidade $(70 \%)$ e textura superficial mamelonada polida (40\%). Estes sedimentos turfáceos apresentam material orgânico particulado com teores entre $2-7 \%$ de carbono total, o que viabilizou uma datação radiocarbônica $(A M S)$ que conferiu a idade de $9.985 \pm 205$ anos AP (Tabela 1). Três horizontes nesta fácies foram amostrados para micropaleontologia (Figura 4), indicando que polens arbóreos (PA) $(3,4-6,8 \%)$ decrescem em direção ao topo da fácies e sendo representado principalmente por Anacardiaceae. 


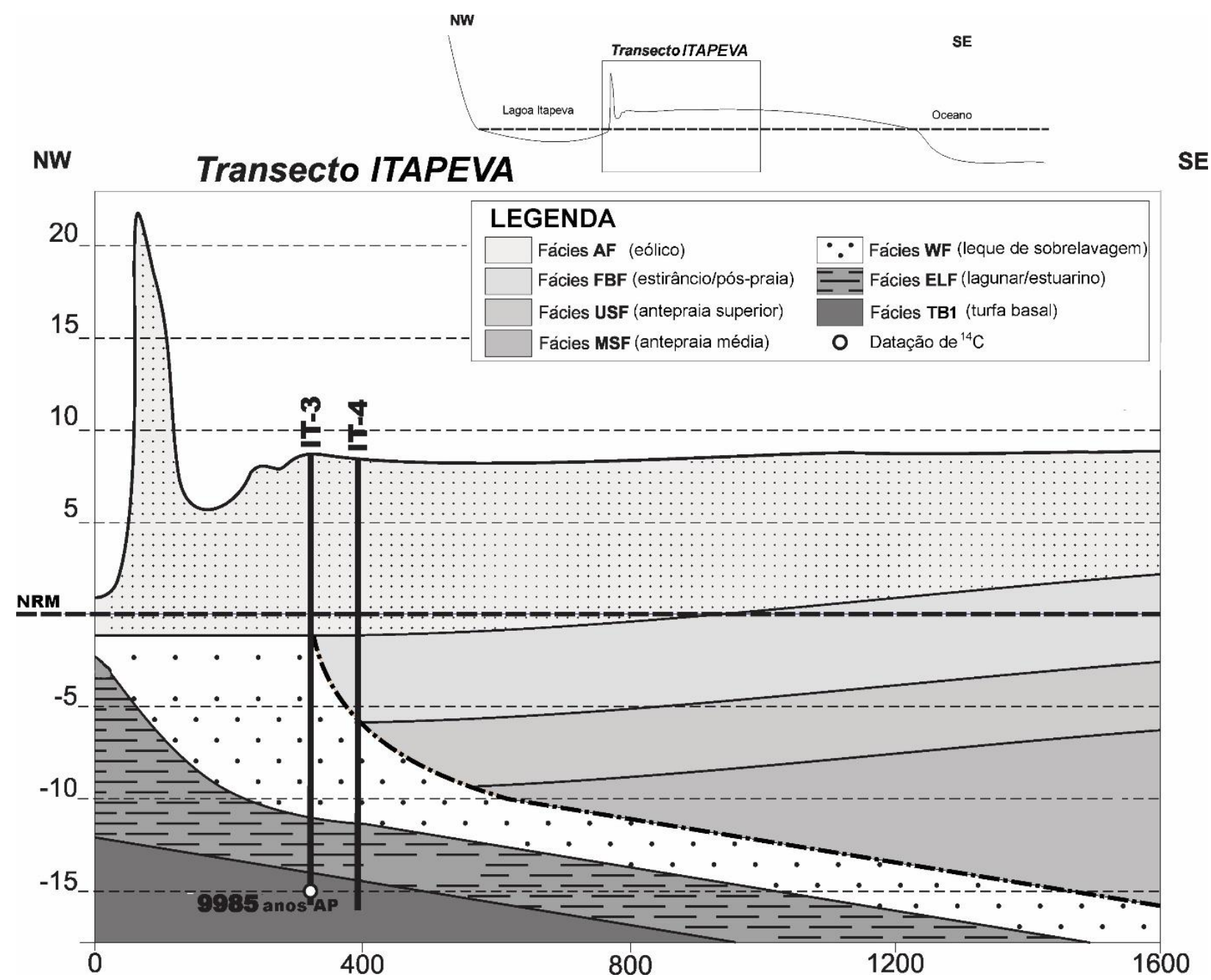

Figura 3 - Seção estratigráfica Itapeva, com destaque para a idade da turfa basal TB1. (modificado de Lima, 2012).

Pólens não-arbóreos-aquáticos (PNAaquáticos) são frequentes, principalmente por Cyperaceae (4,3-9\%) seguido de Typhaceae (3,4-6,8\%) e Polygonum hydropiperoides (0-5,4\%). Pólens não-arbóreos (PNA) ocorrem indicados principalmente por Poacea $(3,4-10,8 \%)$ seguida de Asteraceae $(2,7-5,6 \%)$. Bryophytas $\quad(4,3-12,8 \%)$ são muito representativas nestes níveis principalmente Phaeoceros laevis. Polypodiaceae $(0-5,6 \%)$ reduzem suas frequências em direção ao topo acompanhando o restante das Pteridophytas. Chlorophytas destacadamente diferenciam-se do restante da sondagem pela grande diversidade e frequências alcançadas por Botryococcus (0-6,4\%), Maugeotia (0-11,3\%) e Pediastrum $(0-6,8 \%)$. Fungi comporta muitas hifas $(1-11,2 \%)$ na base e decaindo em direção ao topo da fácies.

Estruturas silicosas representam o caractere diferencial da fácies-PB. Fitólitos do tipo wavytrapezoid (25-59\%) apresentam redução na frequência em direção ao topo da fácies, no entanto sobrepujam as formas dumbbel
$(2,7-11,2 \%)$ e long saddle $(0-15,8 \%)$ na fácies-TB1. Os fitólitos do tipo wavy unidos (0-8\%) ocorrem somente no nível basal e indicam pouco retrabalhamento. Diatomáceas dulcícolas de Eunotia representam até 16,1\% na base. Espículas de esponjas tipo megasclera $(4,8-39,4 \%)$ são também comuns na fácies-TB1.

Na sondagem IT-4 a análise palinológica foi processada a partir de uma lente de lama e resume-se a um único nível indicando $o$ predomínio de Moraceae-Urticacea (3,2\%) dentre AP (Figura 4). PNA-aquáticos resultam unicamente em $P$. hidropiperoides $(6,8 \%)$ e PNA ocorrem principalmente Poaceae $(24,3 \%)$ seguida de $11,4 \%$ de Asteraceae. Bryphytas são comuns com $7,7 \%$ enquanto Pteridophytas não identificadas somam 13,3\%. Fitoclastos ocorrem com $4,1 \%$ e Chlorophytas com 3,6\%. Nesta fácies uma única morfologia de escolecodonte $(9,1 \%)$ foi muito frequente.

\section{Litoral Sul (Hermenegildo)}

Ao Sul da PCRGS na praia do Hermenegildo foram realizadas três sondagens geológicas do 
tipo SPT (FS-27, FS-28 e FS-29) alinhadas transversalmente à linha de costa onde foram interceptadas duas distintas fácies turfáceas (Figura 5). A fácies mais basal nesta localidade encontra-se na interface Holoceno/Pleistoceno sendo denominada fácies TB2, enquanto alguns metros acima, no limite sedimentos holocênicos lagunares e eólicos foi observada a fácies $\mathrm{T}$.

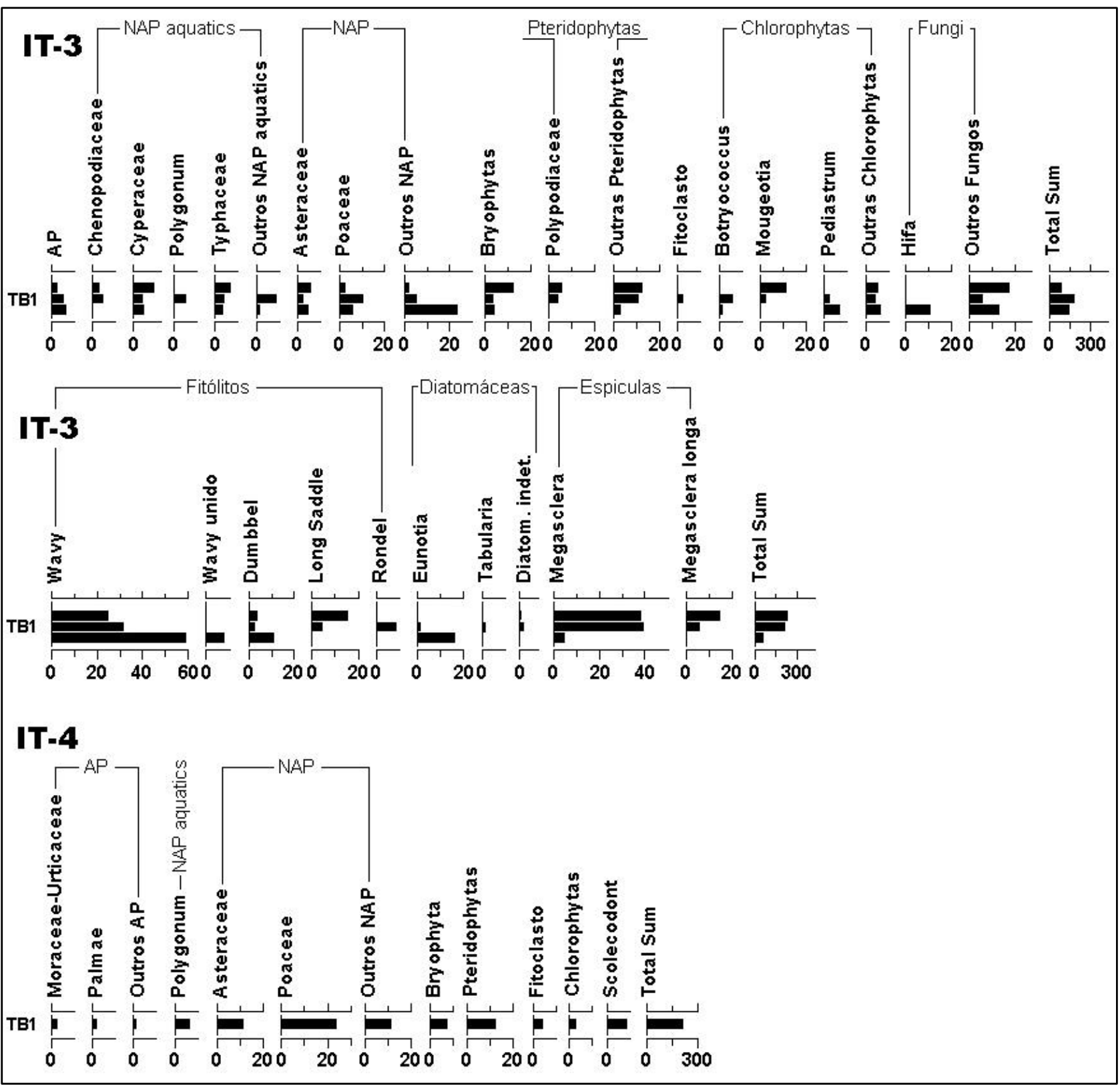

Figura 4 - Palinodiagramas da fácies TB1 das sondagens IT-3 e IT-4.

Tabela 1 - Idades das amostras de ${ }^{14} \mathrm{C}$.

\begin{tabular}{|c|c|c|c|c|}
\hline $\begin{array}{c}\text { amostra/número de } \\
\text { laboratório }\end{array}$ & $\begin{array}{c}\text { material } \\
\text { datado }\end{array}$ & $\begin{array}{c}\text { relação }^{13} \mathrm{C}^{12} \mathrm{C} \\
(\mathbf{o} / \mathrm{oo})\end{array}$ & $\begin{array}{c}\text { idade convencional }\left({ }^{14} \mathrm{C}\right. \\
\text { anos } A P)\end{array}$ & $\begin{array}{c}\text { idade calibrada }^{\text {b }} \\
(\text { anos AP) } \\
\end{array}$ \\
\hline D1/Beta ${ }^{a}-231430$ & Turfa & -25.4 & $780 \pm 40$ & $710 \pm 40$ \\
\hline D2/Beta - 231431 & Sed. orgânico & -25.4 & $8.790 \pm 70$ & $9.855 \pm 305$ \\
\hline IT-3 \#20/Beta - 298863 & Sed. orgânico & -19.9 & $8.890 \pm 40$ & $9.985 \pm 205$ \\
\hline
\end{tabular}

a Beta Analytic, Inc., Miami, Florida, USA. ${ }^{\mathbf{b}} 2$ calibração sigma (95\% probabilidade).

A fácies TB2 tem $1 \mathrm{~m}$ de espessura e seu topo está posicionado a $-1,5 \mathrm{~m}$ em relação ao NRM (Figura 5).

Esta fácies é estratigraficamente análoga a fácies de mesmo nome (fácies TB1) descrita no litoral norte da PCRGS. É predominantemente composta de silte fino, pobremente selecionado, de consistência mole à rija, com 56\% de matéria orgânica (textura particulada e amorfa) e coloração preta (N1). Sua base limita-se a um 
contato gradacional com o substrato pleistocênico. A carga orgânica presente nesta fácies foi submetida à datação ${ }^{14} \mathrm{C}$ (Radiocarbônica) tendo sido obtida a idade de $9.855 \pm 305$ anos AP (tabela 1). Junto ao topo desta fácies ocorrem os moluscos Anomalocardia brasiliana, Paradizia uruguayensis, Heleobia australis e Anadara ovalis. Estas conchas ocorrem associadas a uma grande quantidade de nódulos carbonáticos arredondados. A fácies-TB2 apresenta a maior diversidade de palinomorfos dentre todas as fácies analisadas (Figura 6). Polens de plantas herbáceas perfazem $21,4-25,7 \%$ do total, entre elas as mais significantes Asteraceae, Poligonaceae e Valerianaceae. Polens arbóreos somam 1,1-10,4\% do total, sendo significantes Moraceae-Urticaceae e Cecropia. Pólens não arbóreos aquáticos representam 26,6-57,7\% sendo frequientes Cyperaceae e Chenopodiaceae e Typhaceae. Espóros de Bryophyta (2,4-2,9\%) representados por Anthoceros e Phaeoceros. Pteridophytas $(0,7-1,4 \%)$ foram pouco significativas, ocorrendo Azolla filiculoides, Equisetaceae, Osmunda e Polypodiaceae. Indicadores marinhos são raros, ocorrendo Microforaminíferos $(0,4 \%)$ e Acritarcha Micrhystridium $(0,2 \%)$.

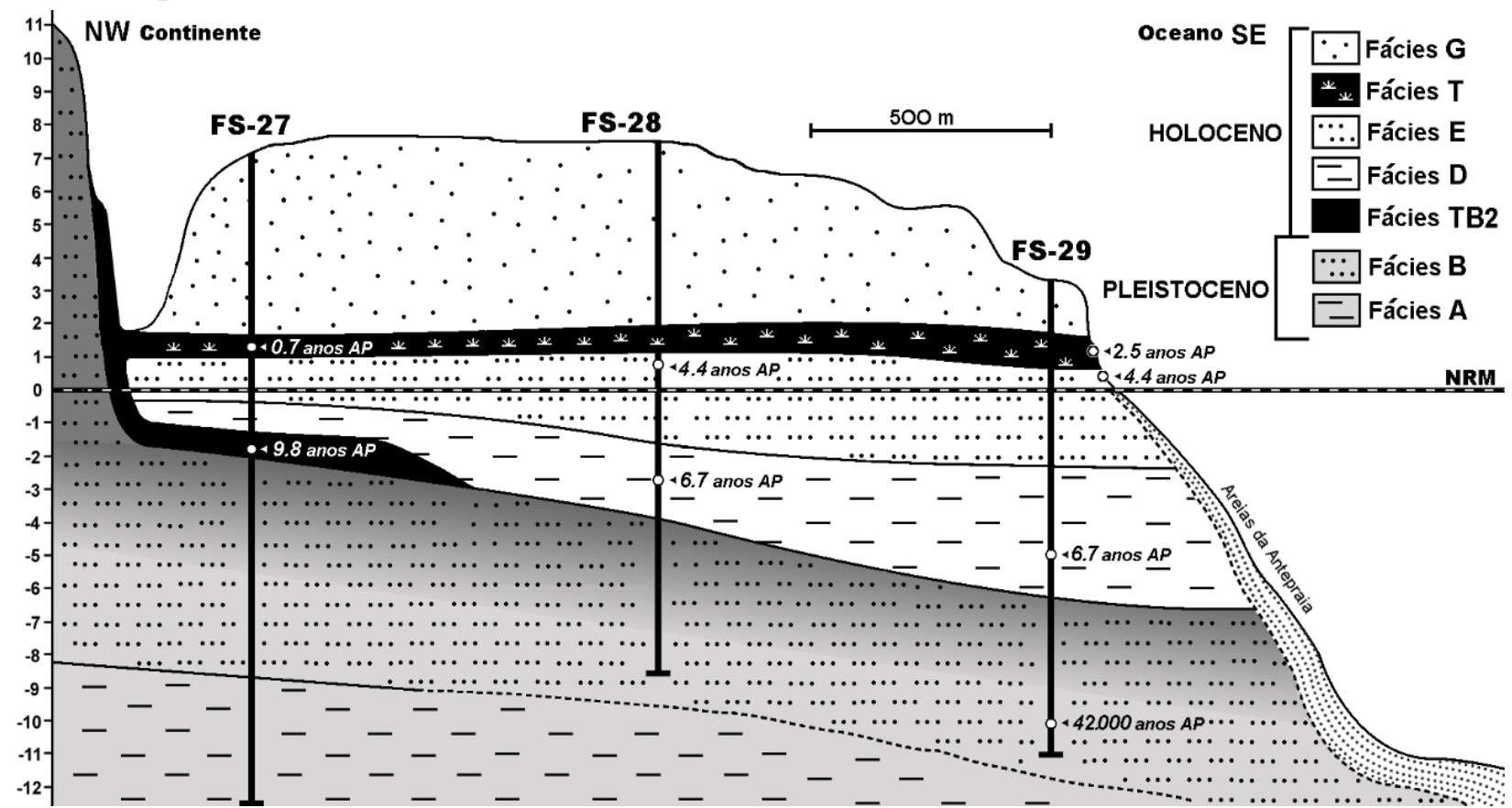

Figura 5 - Seção estratigráfica e respectivas fácies T e TB2 na localidade da praia do Hermenegildo (modificado de Lima et al., 2013).

Diatomáceas de hábito dulcícolas (8,1-20,8\%) Navicula e Pinnularia latevittata e Eunotia, são mais frequentes, seguidas das mixohalinas (0,9-4\%) Surirella, Diploneis, Nitzchia e Rhopalodia. Zigósporos de Chlorophyta $(0,4-0,7 \%)$ são raros, ocorrendo somente Spirogyra e Zygnema. Palinomorfos de fungos indeterminados e Glomus representam 2,2-9,7\% do total. Escolecodontes (mandíbulas de vermes) representam $0,2 \%$ do total da assembleia.

A fácies $\mathrm{T}$ (turfa de topo) tem uma espessura de $1 \mathrm{~m}$, e seu topo está posicionado a $+1,5 \mathrm{~m}$ acima do NRM nas posições mais afastadas da linha de costa e cerca de $+1 \mathrm{~m}$ no estirâncio. Apresenta-se medianamente compactada, com aspecto fibroso e coloração preta (N1); é composta de silte médio, muito pobremente selecionado, e está inserida abruptamente sobre uma fácies lagunar/estuarina.

Teores de $70 \%$ de matéria orgânica conferem a estes sedimentos uma definição de turfáceos. O material orgânico presente na base deste nível foi submetido à datação de ${ }^{14} \mathrm{C}$ (radiométrica), obtendo-se uma idade calibrada entre $710 \pm 40$ anos AP (tabela 1). Lentes de areia enriquecidas em minerais pesados são comuns ao longo da fácies.

$\mathrm{Na}$ fácies $\mathrm{T}$ os polens de plantas herbáceas aquáticas são predominantes $(6,3-67,4 \%)$, pertencendo principalmente a Cyperaceae, Chenopodiaceae, Typhaceae e Polygonum hydropiperoides. Polens de plantas herbáceas (11-45,9\%) principalmente Poaceae seguidas de Apiaceae, Asteraceae e Vigna luteola. Polens de plantas arbóreas $(1,3-17,2 \%)$ são repre- 
sentativos, observando-se principalmente Moraceae-Urticaceae, Anacardiaceae, e Piperaceae, Mimosaceae e Palmae.

As diatomáceas têm sua distribuição marcada pela presença dos táxons dulcícolas (0-50\%) Eunotia, Pinnularia latevittata; de forma secundária, ocorrem as diatomáceas mixohalinas (0-3,3\%) Fragilaria, Nitzchia, Stauroneis e Cymatozira, e marinhas (0-51,6\%) Chaetoceros costatus e Trigonium. Os esporos de Pteridophyta somam $(0,5-41,6 \%)$ sendo indicadas por Azolla filiculoides, Dicranopteris, Equisetaceae, Microgramma, Osmunda e
Polypodiaceae. Os palinomorfos de Chlorophyta (0-50\%) são expressos principalmente por Botryococcus, Spirogyra seguidos de Mougeotia, Zygnema. Esporos de Bryophyta (0-1,3\%) são raros, observando-se Anthoceros e Phaeoceros. Palinomorfos de fungos $(0,5-27,3 \%)$ são frequentes e indicados por Glomus e Tetraploa e indeterminados. Neste nível, há uma grande diversidade de escolecodontes, representando 0$6,8 \%$ do total de palinomorfos. Palinomorfos estritamente marinhos são representados por dinoflagelados de Operculodinium $(0-0,5 \%)$ e Microforaminíferos $(0-3,8 \%)$.

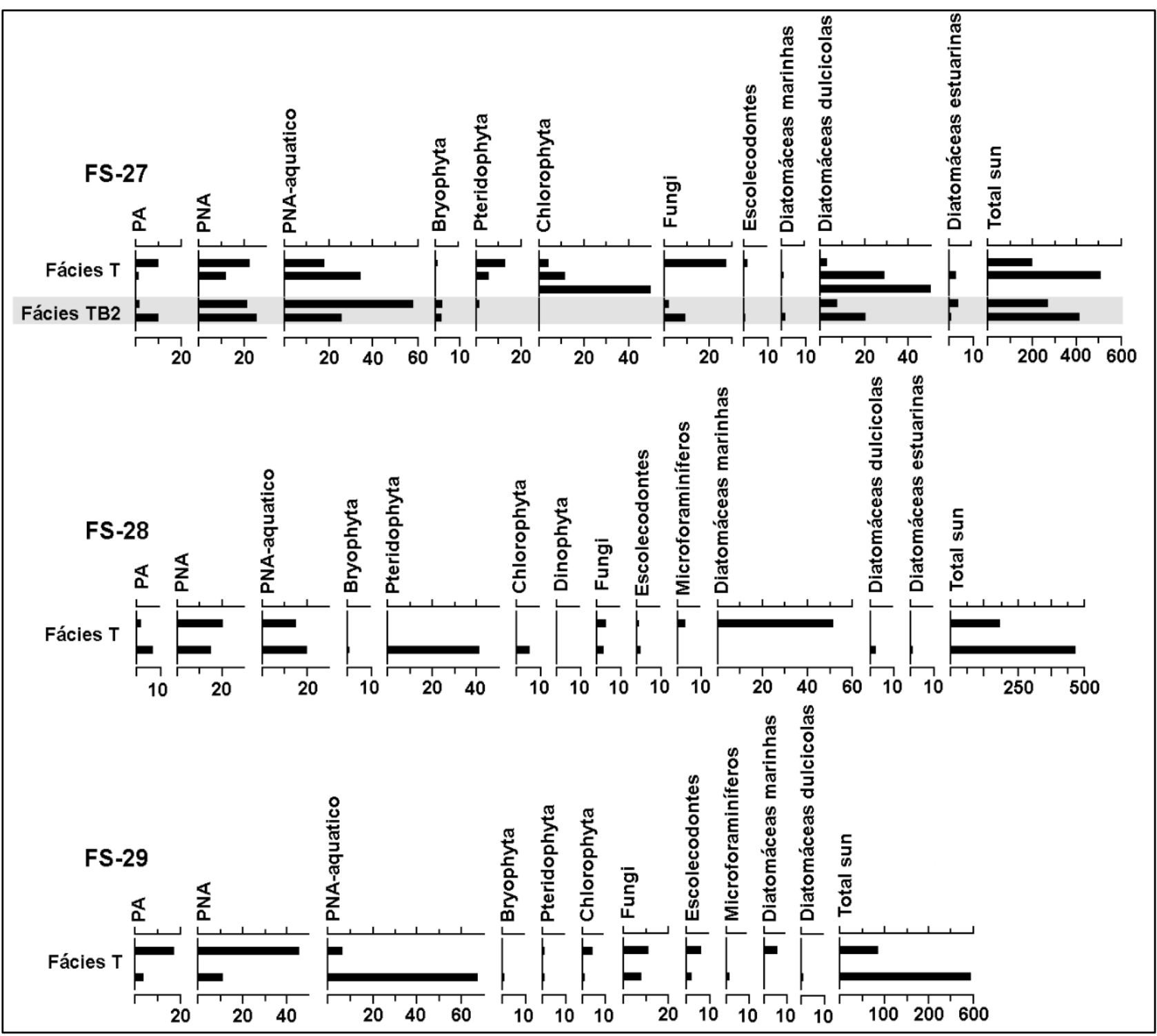

Figura 6 - Palinodiagrama da fácies T e TB2 das sondagens FS-27, FS-28 e FS-29.

Os horizontes turfáceos/carbonosos na localidade da praia do Hermenegildo foram alvo de investigações utilizando-se de Radar de Penetração no Solo (GPR).

A presença destas fácies resulta em refletores extremamente bem definidos nas proximidades das sondagens FS-27 e FS-28 mediante a utilização de antenas de $200 \mathrm{MHz}$ de frequência central (Figura 7).

$\mathrm{Na}$ sondagem FS-29, a menor espessura da turfa e a presença de sais nos sedimentos impossibilitaram a identificação deste horizonte. No perfil executado, os refletores correspondentes as fácies $\mathrm{T}$ apresentam-se 
plano-paralelos, contínuos e de alta amplitude. O aspecto mais marcante quanto a geometria destas fácies refere-se aos refletores concordantes com as fácies inferiores, de forma tabular pontuando o registro com um limite basal muito bem definido.

\section{DISCUSSÃO DOS RESULTADOS}

O estrato basal da sedimentação holocênica está indicado em sequências estratigráficas costeiras pelas chamadas turfas basais (basal peat), sinalizando cronologicamente na PCRGS o início do Holoceno. No litoral sul do RS, na Praia do Hermenegildo, este horizonte corresponde a um paleoambiente paludal composto por turfas amorfas (fácies TB2), situado a cerca de $-1,5 \mathrm{~m}$ abaixo do nível do mar atual, e datadas em $9.855 \pm 305$ anos AP (Tabela 1). Estas turfas assentam-se diretamente sobre o substrato pleistocênico, refletindo uma composição arbórea típica de matas pioneiras e bem adaptadas ao alagamento.

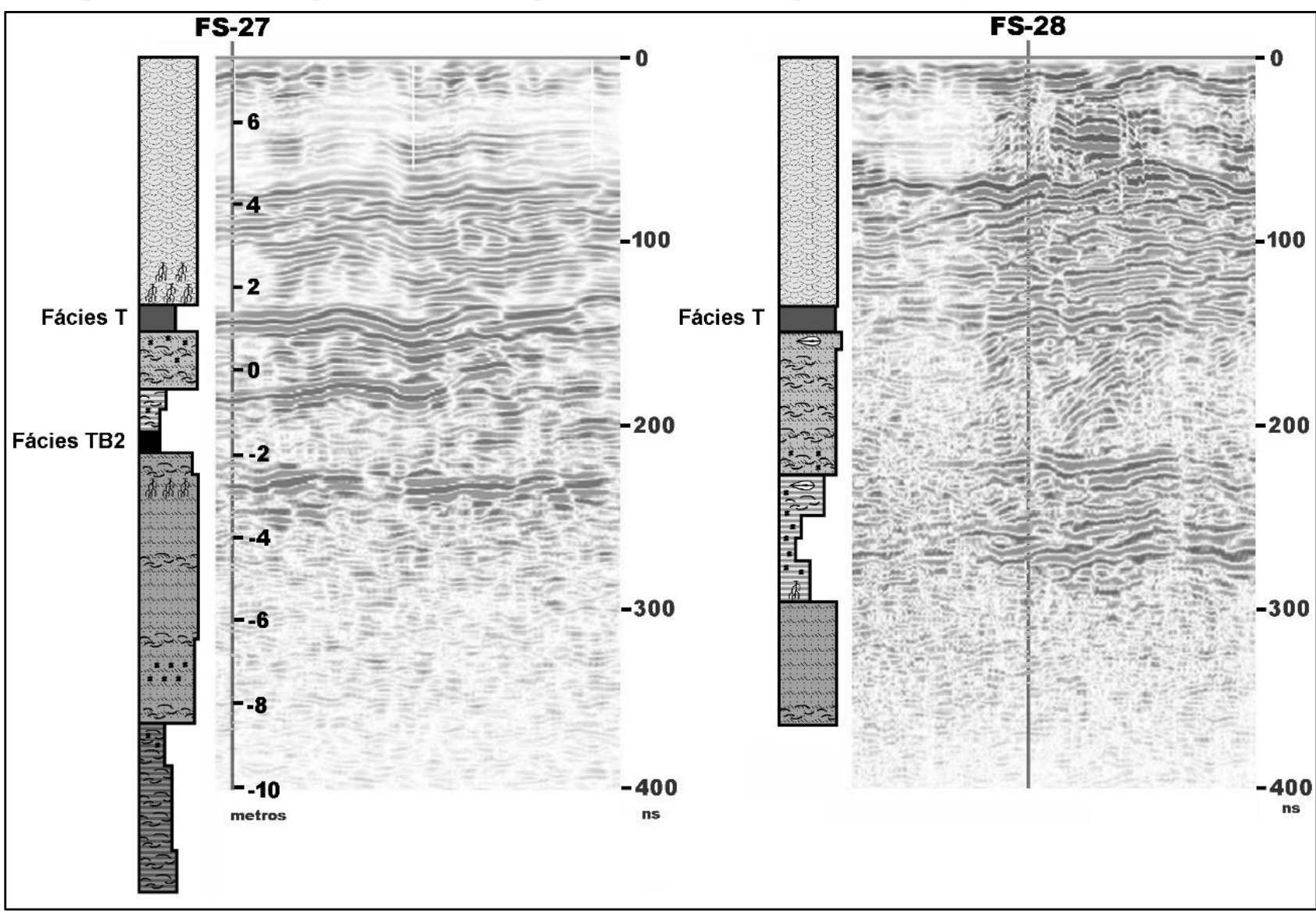

Figura 7 - Seção de GPR interceptando as sondagens FS-27 e FS-28.

A presença desta fácies retrata a existência de um ambiente paludal anterior ao sistema lagunar IV (sensu Villwock, 1984), formado em resposta às elevadas taxas de precipitação no início do Holoceno (Behling, 2002; Behling et al., 2001, 2004). Seu desenvolvimento parece indicar que esta região se encontrava submetida aos regimes hídricos do lençol freático, condicionando áreas permanentemente alagadas em depressões topográficas do substrato pré-holocênico, onde os estratos basais podem ter mais de 38.000 anos AP (Buchmann et al., 1998). Turfas basais podem ainda ser formadas a pequenas profundidades e grandes distâncias da costa quando relacionadas a afluentes tributários nos limites superiores dos estuários ou complexos lagunares, no entanto raramente exedem $20 \mathrm{~m}$ de profundidade do atual NRM (e.g. Törnqvist et al., 2004; Milliken et al., 2018). O registro polínico destas turfas reflete, através de uma grande representatividade de polens arbóreos, sinais de uma melhoria climática no início do Holoceno. No entanto, a presença dos gastrópodes Anomalocardia brasiliana, Paradizia uruguayensis, Heleobia australis e do bivalve Anadara ovalis, inseridos no topo desta fácies, indicam que estes ambientes paludais transitaram gradualmente para ambientes estuarino/lagunares em resposta à progressiva subida do nível do mar durante a TMP. Este nível 
conchífero demarca o primeiro indicio do afogamento de áreas continentais da Planície costeira do Rio Grande do Sul pela invasão marinha.

Este mesmo condicionamento geológico originou, na praia de Itapeva, Litoral Norte do Rio Grande do Sul a fácies TB1, essencialmente arenosa e enriquecida em material orgânico particulado e amorfo. Sua composição micropaleontológica indica novamente uma forte componente palustre principalmente pelas frequências de polens não-arbóreos aquáticos, Chlorophytas, Bryophytas e diatomáceas dulcícolas (Figura 4). Esta condição ambiental desenvolveu-se da mesma forma que a fácies TB2 em resposta à elevação do nível do mar no Holoceno por ocasião da TMP, que determinou também elevação do nível freático regional. Esta fácies representa o primeiro estágio (registro), ainda que continental, da TMP. A sua continentalidade é expressa na ocorrência e diversidade de fitólitos (Figura 4).

A origem das fácies TB1 e TB2 encontra-se relacionada a paleossolos continentais que foram afogados pelo nível do lençol freático que acompanhou o nível do mar em elevação, transpondo ambientes outrora continentais e interiorizados, no curso da transgressão. Esta transição paleossolos/pântanos costeiros ficou registrada na redução nas frequências de fitólitos de opala, polens arbóreos e polens não-arbóreos em direção ao topo da fácies, assim como pelo incremento das frequências de polens nãoarbóreos-aquáticos, Chlorophytas e Bryophytas (Figuras 4 e 6).

Com o decorrer da TMP as posições mais "offshore" (hoje submersas) destas turfas (TB2) foram cobertas pelos sedimentos das barreiras transgressivas; no entanto, para o interior, elas (TB1) ainda são encontradas recobrindo as barreiras pleistocênicas nas cabeceiras de drenagem dos estuários e complexos lagunares atuais. Consideramos que as porções basais destas turfas interiorizadas é que apresentam idades contemporâneas às turfas basais hoje submersas na plataforma continental.

A similaridade entre a fácies TB1 e TB2 quanto a seus aspectos paleoecológicos, cronológicos e estratigráficos, permitem atribuir sua origem a ambientes deposicionais pantanosos que ocuparam a superfície do substrato pleistocênico (Barreira III sensu Villwock, 1984) no início do Holoceno. Estes ambientes foram submetidos a um progressivo encharcamento pelo lençol freático durante a TMP, resultando em concentrações anômalas de grãos com textura superficial mamelonada polida, ocasionada pela corrosão química associada ao $\mathrm{pH}$ ácido das águas (e.g. Bigarella $\&$ Mousinho, 1965) destes ambientes pantanosos. Segundo Lima (2012) estas concentrações são diagnósticas destes depósitos, diferenciando-se das demais fácies sedimentares holocênicas identificadas na PCRGS.

No entanto, não se descarta que podem estar associadas a um certo retrabalhamento do substrato pleistocênico adjacente, onde os grãos mamelonados seriam redepositados junto as turfas basais. Outra evidência deste retrabalhamento resulta da presença de nódulos carbonáticos arredondados e dispersos na fácies TB2. Estes nódulos são oriundos dos sedimentos pleistocênicos, atribuídos ao "caliche cordão" (sensu Delaney, 1962) indicando um grande evento pedogenético que atingiu a superfície das barreiras pleistocênicas desta região (Lopes et al., 2016).

Outro aspecto diagnóstico da fácies TB2 diz respeito a sua continuidade lateral, onde pode ser acompanhada por dezenas de quilômetros em direção ao continente (Figura 8), quando estes ambientes paludais se mesclam a paleossolos em cotas mais elevadas do substrato pleistocênico (Barreira III) (Buchmann et al., 1998; Lima 2004; Lima et al., 2007; Lima et al., 2012). Na atual margem oeste do sistema lagunar holocênico, estas acumulações orgânicas permanecem em constante desenvolvimento, e quando desenvolvidas sobre depressões topográficas, atingem elevadas espessuras (Tomazelli \& Villwock, 1991; Neves \& Lorscheitter, 1996; Bauermann, 2003).

As fácies TB1 e TB2 representam uma fase de melhoria climática (ótimo climático) no início do Holoceno, que enriqueceu com material orgânico os níveis superficiais do substrato pleistocênico, sobre o qual se instalou a sedimentação do sistema lagunar holocênico. Este condicionamento estratigráfico possibilita que a base da fácies TB1 e TB2 possa ser utilizada como referencial da topografia antecedente (préHoloceno) (e.g. Abbott, 1985; Belknap \& Kraft, 1985; Demarest \& Leatherman, 1985; HellandHansen \& Martinsen, 1996). Esta hierarquia estratigráfica permite a correlação regional durante a transgressão, equivalendo estratigra- 
ficamente às denominadas turfas basais (basal peat), e indicando o início da sedimentação holocênica, conforme relatado por diversos autores (e.g. Kraft, 1971; Kraft \& John, 1979; Randall, 1989; Baeteman \& Strijdonck 1989; Beets et al., 1992). Na estratigrafia de sequências, as fácies TB1 e TB2 equivalem ao extremo continental da superfície transgressiva, responsável pela subdivisão transgressão/ regressão (Van Wagoner et al., 1991; Emery \& Myers, 1996; Samuelsberg \& Pickard, 1999; Beets et al., 2003; Amorosi et al.,
2005; Catuneanu et al., 2006).

Nas perfilagens com GPR a fácies TB2 comporta refletores pouco nítidos quando comparado a fácies $\mathrm{T}$, principalmente pela proximidade do substrato pleistocênico, onde elevadas concentrações de nódulos ferruginosos (barreira III) e carbonáticos (formação Cordão) mascaram o sinal desta fácies (Figura 8). Alternativamente esta ausência de sinal pode também estar relacionada a textura da fácies (silte fino).

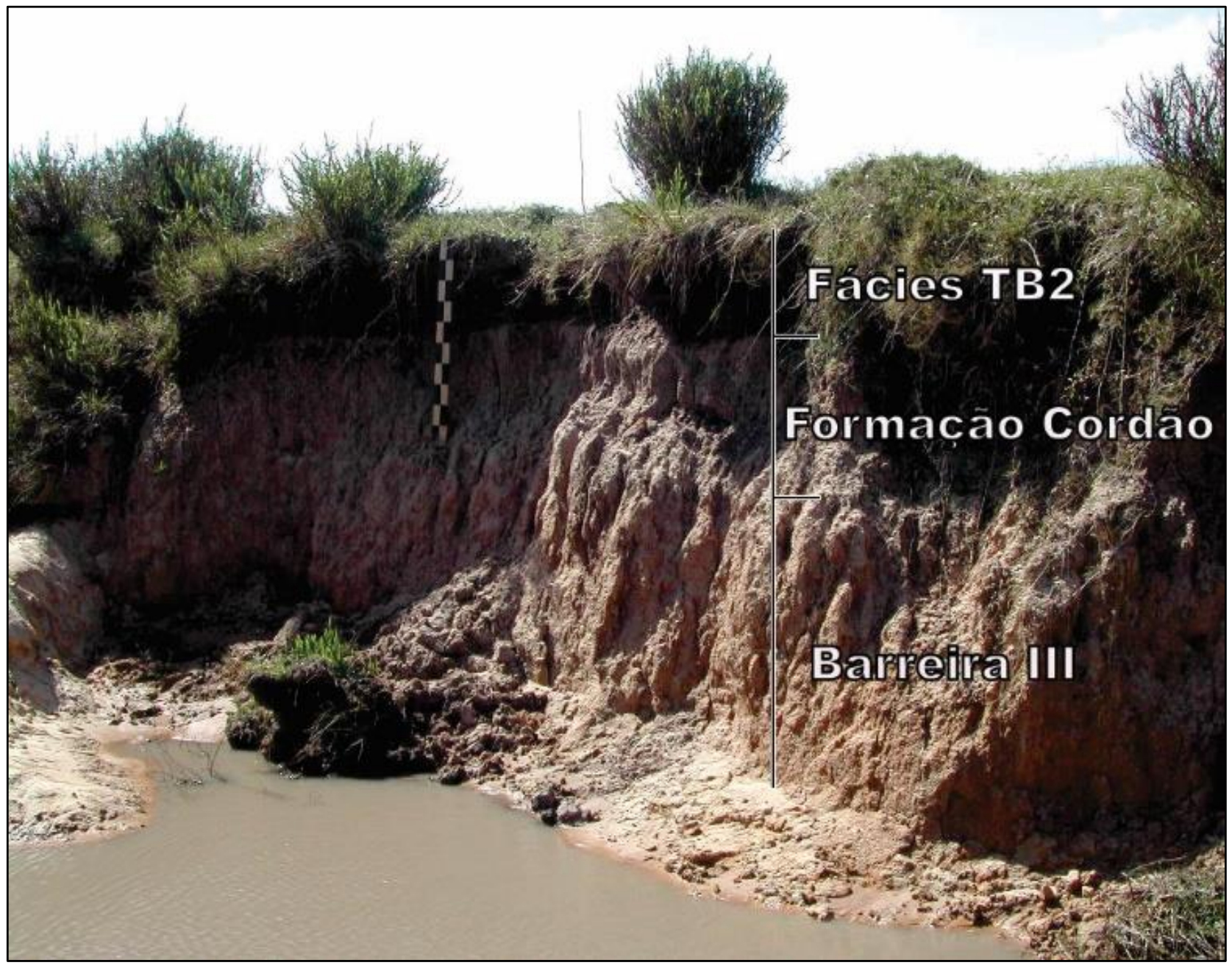

Figura 8 - Detalhe da escarpa erosiva na Barreira III (escala $1 \mathrm{~m}$ ). Nesta escarpa é possível visualizar a continuidade da fácies TB2 estendendo-se sobre a formação Cordão e Barreira III. Notar a cloração avermelhada dos sedimentos em virtude da elevada concentração de nódulos ferrosos.

O outro condicionamento estratigráfico em que se observam acumulações turfáceas na Planície Costeira do Rio Grande do Sul resulta de afloramentos superficiais no estirâncio e póspraia, alcançando dezenas de quilômetros de extensão. Na praia do Hermenegildo estes afloramentos podem ser acompanhados por até 40 km entre o Arroio Chuí e extremo sul da lagoa Mangueira (Buchmann et al., 1998) com idades de 2.470 anos AP (Figuras 2 e 5). Plantas herbáceas aquáticas dominam as análises palinológicas nos horizontes desta turfeira indicando uma comunidade paleovegetacional de pequeno porte e muito bem adaptada ao alagamento. Os estratos superiores destas turfeiras registram organismos (conchas de moluscos) estuarinos e marinhos indicando que a medida que o espaço de acomodação em retrobarreira (sistema lagunar IV) tornou-se preenchido pelo desenvolvimento das turfas, a hidrodinâmica lagunar/estuarina restringiu-se as bordas da turfeira. O resultado disto é a 
preservação de indicadores marinhos e estuarinos somente nos estratos superiores e periféricos da fácies $\mathrm{T}$, confirmando que a evolução destes ambientes deposicionais não ocorre de forma abrupta e sim gradativa. Lima et al. (2012) sugerem que estes ambientes registram a transição laguna/lagoa costeira por volta de 710 \pm 40 anos AP, onde a redução de salinidade foi ocasionada pelo fechamento da conexão entre lagoa e oceano (canais de ligação), resultando no estabelecimento e expansão de uma densa cobertura vegetal de banhados ocupando as seções mais rasas ou então de menor hidrodinamismo da retrobarreira lagunar.

No sentido do continente, esta turfeira (fácies T) estende-se continuamente até alcançar o sistema de barreiras pleistocênicas posicionadas a $2 \mathrm{~km}$ da praia (Figuras 5 e 8). Os refletores associados a deposição da fácies $T$ representam os mais nítidos registros recuperados com GPR na praia do Hermenegildo. Tanto a continuidade como a horizontalidade destes refletores, possibilitam seu fácil reconhecimento com antenas de $200 \mathrm{MHz}$ (Figura 7). Esta continuidade retrata a estabilidade dos níveis do lençol freático ao longo de seu desenvolvimento. Sua gênese decorre de uma situação onde os níveis hidrológicos em retrobarreira são mantidos sobrelevados em relação ao nível do mar (+1 m), como na lagoa Mangueira (Lima \& Buchmann, 2005). É provável que o desenvolvimento deste ambiente paludal tenha se dado a partir da segmentação da retrobarreira por esporões arenosos lagunares (spits) que terminam por restringir a dinâmica lagunar segundo o modelo proposto por Zencovitch (1959). Atualmente este processo verifica-se em ambos os extremos da Lagoa Mangueira (Figura 9). No extremo norte desta lagoa pode ser observado um quadrante (S1) em processo avançado de segmentação pela ampliação de pontais arenosos em ambas as margens da lagoa.

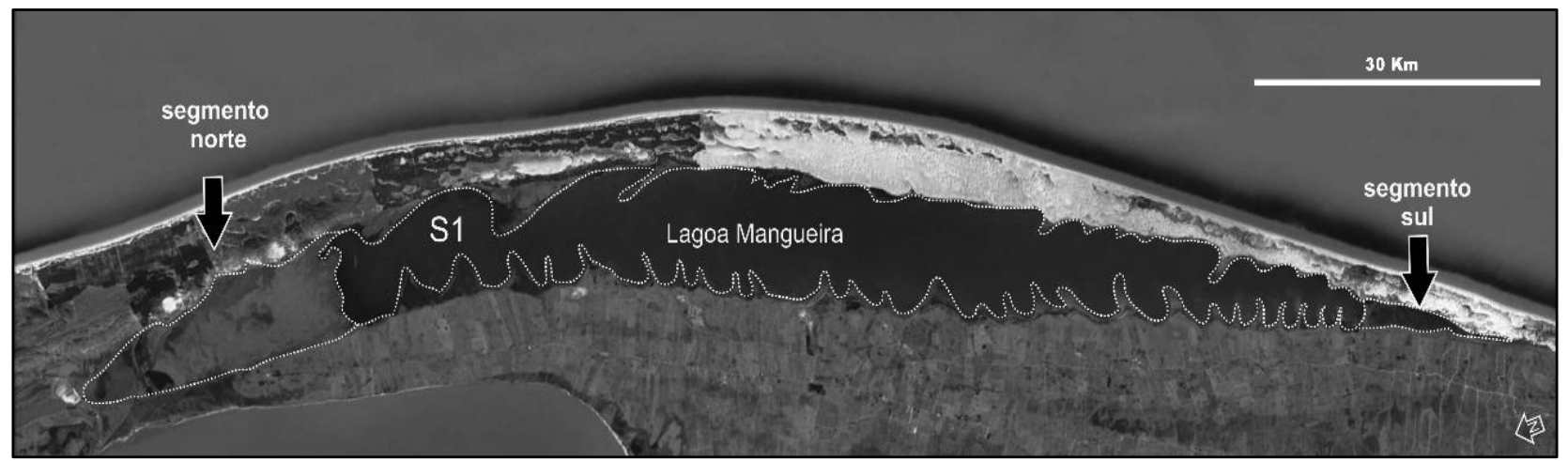

Figura 9 - Formação de pontais arenosos e consequente segmentação lagunar (S1) nos extremos da Lagoa Mangueira. O quadrante S1 encontra-se em processo avançado de segmentação pela evolução dos pontais no limite norte da lagoa.

Segundo Lima (2008) a Barreira IV no setor costeiro da praia do Hermenegildo, corresponde a deposição eólica de dunas transgressivas, as quais recobrem os sedimentos turfáceos (fácies T), definindo uma sequência tipicamente transgressiva. Na localidade do Farol do Conceição, município de Bojuru, turfas com idades semelhantes (405 e 970 anos AP) e também resultantes do assoreamento lagunar por dunas transgressivas foram descritas por Dillenburg et al. (2004). Neste trabalho os autores indicam que a morfologia das barreiras costeiras (barreiras transgressivas) nestes setores litorâneos é a principal condicionante no desenvolvimento destas sequências estratigráficas. Ou seja, ambas as localidades (Hermenegildo e Bojuru) evidenciam o processo de migração das barreiras em direção do continente, tanto pelo soterramento das retrobarreiras por campos de dunas transgressivos como pela exposição dos depósitos de retrobarreira (fácies T) ao nível do pós-praia atual. A migração das barreiras transgressivas em direção do continente leva a uma redução das dimensões da retrobarreira lagunar, tanto horizontais (área) como verticais (profundidade). Os paleoníveis freáticos destas acumulações são preservados pela colmatação promovida pelo sistema eólico adjacente possibilitando determinar aspectos evolutivos relacionados a dinâmica dos sistemas de barreiras costeiras transgressivas. Além disso, a extensão dos afloramentos turfáceos no pós-praia servem como referencial, não só da migração em direção do continente destas barreiras costeiras, mas também de sua variação (mudança de sua natureza) ao longo da costa. Esta variação longitudinal, de sul para norte (barreiras 
transgressivas sendo transformadas em barreiras anexadas - mainland beach barriers), resulta na exposição progressiva, de sul para norte, na praia atual, da topografia antecedente representada pela barreira III (pleistocênica) (Figuras 10 e 11).

$\mathrm{Na}$ praia do Hermenegildo as acumulações turfáceas são mais expressivas em direção do oceano, com até um metro de espessura, da mesma forma que as fácies lagunares/estuarinas imediatamente sobrepostas pelas turfeiras (Buchmann et al., 1997; Lima et al., 2012). O topo das turfas aflorantes no estirâncio encontrase rebaixado cerca de meio metro em relação a sua posição mais continental, no limite com os depósitos pleistocênicos (Barreira III), indicando que o maior espaço de acomodação do sistema lagunar encontrava-se vinculado a margem oceânica do complexo lagunar. Isto é, à medida que o sistema eólico avança sobre a retrobarreira, ocorre também um represamento do sistema lagunar, elevando os níveis freáticos regionais.

Num contexto evolutivo, existiu uma fase anterior ao máximo transgressivo de 5.600 anos AP, onde barreiras costeiras pré-existentes, localizadas a uma certa distância da atual linha de costa (área atualmente afogada de plataforma continental) responderam essencialmente ao fator glacioeustático, levando a uma ocupação progressiva das depressões lagunares por ambientes paludais (fácies TB1 e TB2). Conforme a TMP prosseguiu estes ambientes paludais foram sendo sobrepostos gradativamente pela migração de ambientes estuarinos/lagunares na retaguarda das barreiras costeiras, como indicado pelos moluscos estuarinos inseridos no topo das turfas basais (fácies TB1 e TB2). Estes ambientes permaneceram com suas conexões com o oceano ativas, até o fechamento dos canais de ligação que mantinham as trocas entre a laguna e o oceano. Este fechamento dos canais foi contemporâneo ao abaixamento do nível do mar, entre 2 e $3 \mathrm{~m}$, ocorrido após o nível de mar mais alto ocorrido há cerca de 5.600 anos AP. Este isolamento promoveu uma nova fase paludal em retrobarreira onde desenvolveram-se novamente ambientes pantanosos (fácies $\mathrm{T}$ ) em compartimentos rasos e isolados da hidrodinâmica lagunar (ondas), condicionados por spits lagunares.

A relativa estabilidade que seguiu o máximo da TMP, fez com que estas barreiras passassem a ser controladas por condicionantes regionais que influenciaram, por exemplo, o balanço de sedimentos costeiros (Dillenburg et al., 2000, Dillenburg et al., 2009, Lima et al., 2012).

Assim, diferentes balanços sedimentares foram estabelecidos ao longo do litoral, promovidos em parte, por variáveis da deriva litorânea de sedimentos ocasionando no litoral do Rio Grande do Sul extensos setores em progradação, retrogradação e agradação da barreira costeira holocênica (Dillenburg et al., 2009). O sentido preferencial N-NE deste transporte longitudinal de sedimentos, coordenou a geometria dos cordões litorâneos nos setores em progradação. Da mesma forma, parte da área fonte para os setores em progradação foram exatamente os setores em retrogradação situados ao sul das áreas em progradação.

Desta forma, segundo Dillenburg et al. (2000), Dillenburg (2004) e Lima et al. (2013), houve uma continuidade do processo transgressivo, após o máximo do nível relativo do mar alcançado há 5.600 anos AP, mesmo sob uma condição de quase estabilidade, ou de um lento rebaixamento do nível do mar, decorrente de um balanço negativo de sedimentos, operante em uma escala secular e milenar.

$\mathrm{Na}$ região da praia do Hermenegildo, foi postulada a hipótese de que o balanço negativo de sedimentos, operante em escala de longo termo, é resultante da retenção de areia por promontórios rochosos da costa uruguaia. Estes promontórios foram estabelecidos como tais, após atingido o nível de mar mais alto de 5.600 anos AP, quando passaram a reter parte dos sedimentos da deriva litorânea, gerando assim um balanço negativo de sedimentos na região do balneário Hermenegildo (Lima \& Dillenburg, 2007).

Da mesma forma, o balanço negativo de sedimentos operante em escala secular e milenar na região de Bojuru, resulta de um déficit de sedimentos ocasionado de duas formas principais tendo como motor à deriva litorânea de sedimentos: 1- os sedimentos são removidos deste setor costeiro onde a deriva apresenta suas maiores taxas de transporte (Lima et al., 2001), e 2- os sedimentos são aprisionados no setor ao sul da desembocadura da Lagoa dos Patos na cidade de Rio Grande (Dillenburg et al., 2000). Esta desembocadura retém sedimentos tanto pelo efeito molhe (Komar, 1973), como pelo efeito de redirecionar os sedimentos até profundidades 
além da profundidade de fechamento (Hallermeier, 1981) impossibilitando seu retorno ao prisma litorâneo.

Uma estimativa dos processos relacionados ao transporte longitudinal de sedimentos na costa gaúcha foi reportada por Lima et al. (2001) indicando que as ondulações do quadrante sul são responsáveis por mais de $30 \%$ do transporte longitudinal total, enquanto que os regimes de ondulação do quadrante N-NE representam menos de $2 \%$ da deriva total. Ainda, neste estudo foi compreendido que os setores da praia do Hermenegildo e Farol do Conceição (município de Bojuru) representam as localidades com as maiores taxas de deriva na ordem de 2.600 .000 $\mathrm{m}^{3}$ /ano em sentido NE.

Apesar dos afloramentos das turfas no estirâncio e pós-praia ocorrerem em setores distintos, uma série de similaridades (orientação da linha de costa, cronologia e estratigrafia dos depósitos) sugere que estes afloramentos resultam dos mesmos processos geomorfológicos.

Num contexto geomorfológico amplo, estes depósitos encontram-se vinculados a porção sul de grandes projeções costeiras que segundo Dillenburg et al. (2000) refletem a topografia antecedente, constituindo-se, em uma herança geológica onde sutis variações no declive da plataforma continental são acompanhadas por variações da orientação da linha de costa. Assim nas reentrâncias e projeções costeiras, desenvolvem-se respectivamente, barreiras regressivas e transgressivas.

Os afloramentos de turfas na linha de costa da praia do Hermenegildo e Farol do Conceição indicam que o contorno litoral moderno (atual) em ambos os setores, encontram-se em desacordo com o contorno litoral que originou tais deposições. Estes dois segmentos litorâneos em que os ambientes deposicionais paludais (pântanos e banhados formadores de turfas) afloram no estirâncio deveriam ser mais alongados projetando-se ao sul, porém sempre ancorados as barreiras pleistocênicas na sua margem oeste. Esta configuração pretérita da linha de costa do RS durante o máximo eustático foi modelada por Dilllenburg et al. (2000) servindo como pano de fundo para a compartimentação atual dos sistemas de barreiras holocênicas. A figura 10 representa uma adaptação deste modelo evolutivo, em que se tornam aflorantes os depósitos de retrobarreira (turfas) no estirâncio, na medida em que a linha de costa migra no sentido do continente e modifica a natureza da barreira longitudinalmente, de sul para norte.

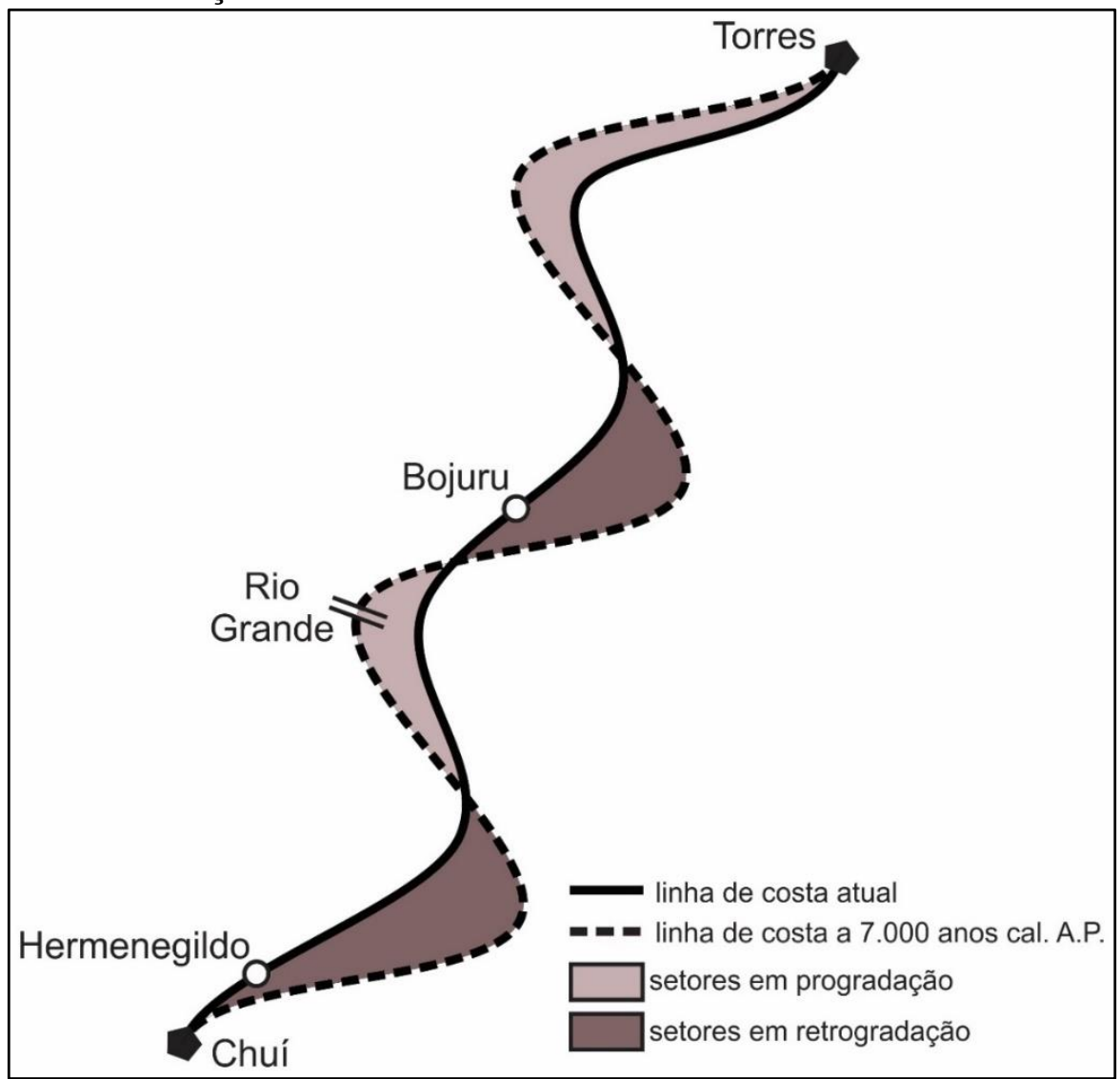


Figura 10 - Modelo conceitual de evolução da linha de costa no RS nos últimos 7.000 anos A.P. (adaptado de Dillenburg et al., 2000).

Os pântanos costeiros que originaram as turfas aflorantes na atual linha de costa provavelmente tiveram sua origem na retrobarreira lagunar vinculada aos extremos sul de duas grandes lagunas: a laguna do Peixe e Lagoa Mangueira. No limite sul de ambas localidades são encontrados sedimentos pleistocênicos aflorantes na linha de costa indicando claramente que o processo de reorientação da linha de costa atual, comprime ou até mesmo erode os sistemas laguna-barreiras nos seus limites sul. Na praia do Hermenegildo, este limite (turfas holocênicas/Barreira III) ocorre com afloramentos da barreira III diretamente na linha de costa (Figura 11 a e b).

$\mathrm{Na}$ localidade do Farol do Conceição este limite entre turfas holocênicas e os sedimentos da Barreira III é ocupado por arenitos praiais no estirâncio com idade determinada por Termoluminescência em 109.000 anos barreiras pleistocênicas.

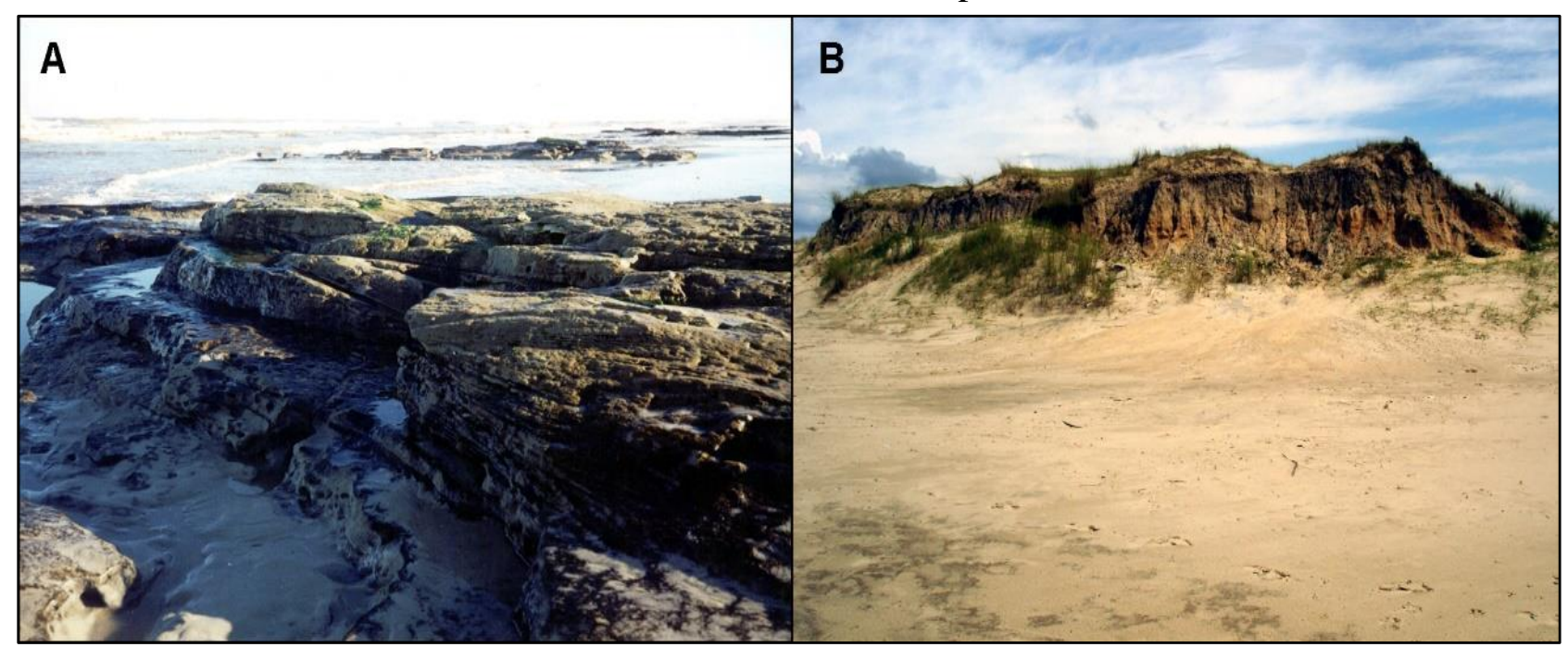

Figura 11 - Afloramentos da Barreira III na linha de costa. A) Depósitos arenosos da barreira III, parcialmente litificados, aflorantes na região do Farol da Conceição e datados em 109.000 anos AP (Termoluminescência) por Buchmann e Tomazelli (2003); B) Afloramento de depósitos arenosos da barreira III (Pleistoceno) na praia do Hermenegildo.

\section{CONCLUSÃO}

O início da sedimentação holocênica na PCRGS, coincidiu com a formação de ambientes paludais de água doce (turfas basais). Estes ambientes ocuparam a superfície pleistocênica (topografia antecedente à última transgressão) na região que viria a se tornar a depressão lagunar holocênica. Os aspectos bioestratigráficos das fácies descritas permitem demonstrar que a 10.000 anos AP ainda prevaleciam condições essencialmente lacustres, com a dominância de vegetação herbácea e hidrófita nas posições onde viriam a se desenvolver os sistemas de barreiras
(Buchmann \& Tomazelli, 2003).

Em ambos os setores onde afloram sedimentos pleistocênicos na linha de costa (Bojuru e Hermenegildo), as barreiras retrogradantes assumem o extremo morfotipo retrogradante chamado praias anexadas (mainland beach) indicando a quase ausência de sedimentos holocênicos (Dillenburg et al., 2000).

A interface de afloramentos (sedimentos pleistocênicos/turfas) tanto na localidade do Hermenegildo como no Farol da Conceição indica que a linha de costa atual do Rio Grande do Sul encontra-se num processo continuo de reorientação, que tem como consequência a ampliação dos setores retrogradantes em direção geral norte. Da mesma forma, a retrogradação nestes setores impõe a migração das barreiras no sentido do continente reduzindo gradativamente o espaço de acomodação ao aproximarem-se das costeiras holocênicas. A compartimentação atual das barreiras costeiras do Rio Grande do Sul foi iniciada após o término da TMP e, por volta de 710 anos AP, instalou-se um novo ambiente paludial (fácies T), agora vinculado à redução das profundidades dos sistemas lagunares holocênicos em processo de colmatação.

Os dados apresentados neste estudo representam uma contribuição ao estabelecimento do modelo evolutivo e paleogeográfico do sistema laguna barreira VI, especificamente nos setores de barreiras 
transgressivas (retrogradantes), onde a linha de costa atual encontra-se num processo continuo de reorientação devido a um déficit de sedimentos, modificando-se tanto em sentido do continente como longitudinalmente de sul para norte, e assim expondo sistematicamente depósitos pleistocênicos seguidos de turfáceos holocênicos na atual linha de costa.

\section{AGRADECIMENTOS}

Os autores agradecem ao financiamento do CNPq No.476189/2009-8 e o segundo autor agradece a Bolsa de Produtividade CNPq No.305393/2017-0.

\section{REFERÊNCIAS}

ABBOTT, W.O. The recognition and mapping of a basal transgressive sand from outcrop, subsurface, and seismic data. In: BERG, O.R., WOOLVERTON, D.G. (Ed.), Seismic Stratigraphy II: An Integrated Approach to Hydrocarbon Exploration, p. 156-169, 1985.

AMOROSI A.; CENTINEO M.C.; COLALONGO M.L.; FIORINI, F. Millennial-scale depositional cycles from the Holocene of the Po Plain, Italy. Marine Geology, v. 223, n. 1, p. 7-18, 2005.

AREJANO, T.B. Geologia e evolução holocênica do Sistema Lagunar da Lagoa do Peixe, litoral médio do Rio Grande do Sul, Brasil. Porto Alegre, 2006. 88 p. Tese (Doutorado), Instituto de Geociências, Universidade Federal do Rio Grande do Sul.

BAETEMAN, C. \& VAN STRIJDONCK, M. Radiocarbon dates on peat from the Holocene coastal deposits in West Belgium. In: BAETEMAN, C. (Ed.): Quaternary sea-level investigations from Belgium. p. 59-91, 1989.

BAUERMANN, S.G. Análises palinológicas e mudanças paleovegetacionais e paleoambientais nas turfeiras de Barrocadas e Águas Claras, Planície Costeira do Rio Grande do Sul, Brasil. Porto Alegre, 2003. 137 p. Tese de doutorado, Programa de Pós-Graduação em Geociências, Instituto de Geociências, Universidade Federal do Rio Grande do Sul.

BEETS, D.J.; VAN DER VALK L.; STIVE M.J.F. Holocene evolution of the coast of Holland. Marine Geology, v. 103, p. 423-443, 1992.

BEETS, D.J.; De GROOT, T.A.M.; DAVIES, H.A. Holocene tidal backbarrier development at decelerating sea-level rise: a 5 millennia record, exposed in the western Netherlands. Sedimentary Geology, v. 158, p. 117-144, 2003.

BEHLING, H. A high resolution Holoceno pollen record from Lago do Pires, SE Brazil: vegetation, climate and fire history. Journal of Paleolimnology, v. 14, p. 253-268, 1995.

BEHLING, H. South and southest brazilian grasslands during Late Quaternary times: a synthesis. Palaeogeograph, Palaeoclimatology, Palaeoecology, v. 117, p. 19-27, 2002.

BEHLING, H.; BAUERMANN, S.G.; NEVES, P.C.P. Holocene environmental changes in the São Francisco de Paula region, southern Brazil. Jounal of South American Earth Science, n. 14, p. 631-639, 2001

BEHLING, H.; PILLAR, V.; BAUERMANN, S.G. Late Quaternary Araucaria forest, grassland (campos), fire and climate dynamics, inferred from a high-resolution pollen record of Cambará do Sul in southern Brazil. Palaeogeograph, Palaeoclimatology, Palaeoecology, v. 203, p. 277-297, 2004.

BELKNAP, D.F. \& KRAFT, J.C. Influence of antecedent geology on stratigraphic preservation potential and evolution of Delaware's barrier systems. Marine Geology, v. 63, n. 1-4, p. 235-262, 1985.

BIGARELLA, J.J. \& MOUSINHO, M. R. Movimentos de massa no transporte dos detritos da meteorização das rochas. Boletim Paranaense de Geografia, v. 17, p. 43-84, 1965.

BIGARELLA, J.J.; HARTKOPF, C.C.; SOBANSKI, A.; TREVISAN, N. Textura superficial dos grãos de areias e arenitos (Contribuição à metodologia). Curitiba, Arq. Biol. Tecn. V. X, n. 11, p. 253-275, 1955.
BUCHMANN, F.S.C. Banhado do Taim e Lagoa Mangueira: Evolução holocênica da paleoembocadura da Lagoa Mirim, RS, Brasil. Porto Alegre, 1997. 155p. Dissertação (Mestrado), Instituto de Geociências, Universidade Federal do Rio Grande do Sul.

BUCHMANN, F.S.C. \& TOMAZELLI, L.J. Relict nearshore shoals of Rio Grande do Sul, Southern Brazil: Origin and effects on nearby modern beaches. Journal of Coastal Research, v. 35, p. 318-322, 2003.

BUCHMANN, F.S.C.; BARBOSA, V.P.; VILLWOCK, J.A. Sedimentologia e paleoecologia durante o máximo transgressivo holocênico na Lagoa Mirim, RS, Brasil. Acta Geologica Leopoldensia, v. XXI, n. 46/47, p. 21-26, 1998.

CALLIARI, L.J. \& PEREIRA DA SILVA, R. Erosion Processes associated to storm surge and washout along the south Brazilian coastline. Journal of Coastal Research, v. 26, p. 1-7, 1998.

CALLIARI, L.J.; TOZZI, H.M.; KLEIN, A.H. Erosão associada a marés meteorológicas na costa sul-rio-grandense. In: CONGRESSO BRASILEIRO DE GEOLOGIA, 34, 1996, Salvador. Anais... Salvador: Sociedade Brasileira de Geologia, 1996, v.1, p. 430-434.

CATUNEANU, O. Principles of sequence stratigraphy. Amsterdam, Elsevier, 2006, 375 p.

CORDEIRO, S.H. \& LORSCHEITTER, M.L. Palynology of Lagoa dos Patos sediments, Rio Grande do Sul, Brazil. Journal of Paleolimnology, v. 10, p. 35-42, 1994

CORREAA, I.C.S.; WESCHENFELDER, J.; TOLDO JR, E.E.; RICARDO BAITELLI, R.; SANTOS-FISCHER, C.B. Gênese de um Depósito de Turfa na Plataforma Continental do Rio Grande do Sul -Brasil. Quaternary and Environmental Geosciences, v. 6, n. 2, p. 1-9, 2015

COWELL, P.J.; ROY, P.S.; CLEVERINGA, J.; DE BOER, P.L. Simulating coastal systems tracts using the ShorefaceTranslation Model, International Association of Sedimentologists Special Publication, v. 62, p. 165-175, 1999.

DELANEY, P.J.V. Quaternary Geologic History of the Coastal Plain of Rio Grande do Sul, Brazil. South American Coastal Studies Technical Reports, v. 18(part A), p. 63, 1962.

DEMAREST, J.M. \& LEATHERMAN S.P. Mainland influence on coastal transgression: Delmarva Peninsula. Marine Geology, v. 63, n. 1, p.19-33, 1985:

DILLENBURG, S.R.; ROY, P.S.; COWELL, P.J.; TOMAZELLI, L.J. Influence of antecedent topography on coastal evolution as tested by the shoreface translation-barrier model (STM). Journal Coastal Research, v. 16, p. 71-81, 2000 .

DILLENBURG, S.R.; TOMAZELLI, L.J. BARBOZA, E.G. Barrier evolution and placer formation at Bujuru southern Brazil. Marine Geology, v. 203, p. 43-56, 2004

DILLENBURG, S.R.; BOZA, E.G.; TOMAZELLI, L.J.; HESP, P.A.; CLEROT, L.C.P.; AYUP-ZOUAIN, R.N. The Holocene Coastal Barriers of Rio Grande do Sul. In: DILLENBURG, S.R. \& HESP, P.A. (Eds.), Geology and Geomorphology of Holocene Coastal Barriers of Brazil. Berlin, Springer, v. 107, p. 53-91, 2009.

DOMINGUES, J.M.L.; MARTIN, L.; BITTENCOURT, A.C.S.P. Sea-level history and Quaternary evolution of river 
mouth-associated beach-ridge plains along the east-southeast Brazilian coast: a summary. In: NUMMEDAL, D.; PILKEY, O.H.; HOWARDS, J.D. (Eds) Sea-level fluctuation and coastal evolution, Special Publication of the Society of Economic Paleontologists and Mineralogists, v. 41, p. 115-127, 1987

EMERY, D. \& MYERS, K.J. Sequence Stratigraphy. London: Blackwell Science, 297 pp. 1996.

EVANS, M. \& WARBURTON, J. The geomorphology of upland peat: pattern, process, form. Blackwell, Oxford. 281 p. 2007.

FAEGRI, K. \& IVERSEN, J. Textbook of pollen analysis. 4th ed. New York, John Wiley \& Sons, Chichester, 328p. , 1989.

FIELD, M.E., \& DUANE, D B. Geomorphology and Sediments of the Inner Continental Shelf, Cape Canaveral, Florida. US Army Engineer Waterways Experiment Station. CERC No. 42. 1974.

GOUVEIA, S.E.M. Dinâmica de vegetações durante o Quaternário recente no sul do Amazonas, indicadas pelos isótopos de carbono $(12 \mathrm{C}, 13 \mathrm{C}, 14 \mathrm{C})$ do solo. Geochimica Brasiliensis, v. 11, n. 3, p. 355-367,1997.

GREGORY, W.A. \& HART, G.F. Towards a Predictive Model for the Palynologic Response to Sea-Level Changes. Palaios, 7: 3-33. 1992.

HALLERMEIER, R.J. A profile zonation for seasonal sand beaches from wave climate, Journal of Coastal Engineering, 4: 253-277. 1981.

HELLAND-HANSEN, W. \& MARTINSEN, O.J. Shoreline trajectories and sequences: description of variable depositionaldip scenarios: Journal of Sedimentary Research, v. 66, p. 670-688, 1996

HUGHEN, K. A. et al. 2004. Marine04 Marine Radiocarbon Age Calibration, 0-26 Cal kyr BP. Radiocarbon, 46(3): 1059-1086.

HUNT, C.O. Dinoflagellate cyst and acritarch assemblages in shallow-marine and marginal-marine carbonates: the Portland Sand, Portland stone and Purbeck Formation (Upper Jurassic/Lower Cretaceous) of Southern England and Northern France. In: Micropaleontology of Carbonate Botryococcus Environments of Ellis Horwood. Chichester, p. 208-225, 1987.

KOMAR, P.D. Computer Models of Delta Growth due to Sediment Input from Rivers and Longshore Transport. Geological Society of America Bulletin, v. 84, p. 2217-2226, 1973.

KRAFT, J.C. \& JOHN, C.J. Lateral and vertical facies relations of transgressive barrier: AAPG, v. 63, p. 2145-2163, 1979,

KRAFT, J.C. Sedimentary facies patterns and geologic history of a Holocene marine transgression. AAPG, v. 82, p. 2131-2158, 1971.

KRUMBEIN, W.C. Measurements and geologic significance of shape and roundness of sedimentary particles. Journal of Sedimentary Petrology, v. 11, p. 64-72, 1941.

LIMA, L.G. 2008. Estratigrafia e evolução da barreira holocênica na Praia do Hermenegildo (RS). Porto Alegre. 72 p. Dissertação (Mestrado), Instituto de Geociências, Universidade Federal do Rio Grande do Sul.

LIMA, L.G. Estratigrafia E Evolução Holocênica De Uma Barreira Costeira Transgressiva/Regressiva, Litoral Norte Do Rio Grande Do Sul, Brasil. Porto Alegre, 2012. 128 p. Tese (Doutorado), Instituto de Geociências, Universidade Federal do Rio Grande do Sul.

LIMA, L.G. \& BUCHMANN, F.S.C. Novo Afloramento Fossilífero (Pleistoceno/Holoceno) no Sul da Planície Costeira do Rio Grande do Sul. In: X CONGRESSO DA ABEQUA, 2005, Guarapari, ES. Anais... ABEQU. v.1, p. 143, 2005.

LIMA, L.G. \& DILLENBURG, S.R. O Litoral do Uruguai e a evolução geológica das barreiras costeiras do Rio Grande do Sul. In: CONGRESO URUGUAYO DE GEOLOGIA, 5, 2007, Montevideo. Anais... Montevideo, v. 1, p. 87, 2007.

LIMA, S.F.; ALMEIDA, L.E.S.B.; TOLDO JR., E.E. Estimate of longshore sediments transport from waves data to the Rio
Grande do Sul coast. Pesquisas, v. 28, n. 2, p. 99-107, 2001.

LIMA, L.G.; DILLENBURG, S.R.; MEDEANIC, S.; BARBOSA, E.G.; ROSA, M.L.C.C.; TOMAZELLI, L.J.; DEHNHARDT, B.A.; CARON, F. Sea-level rise and sediment budget controlling the evolution of a transgressive barrier in southern Brazil. Journal of South American Earth Sciences, v. 42, p. 27-38, 2013

LOPES RP.; DILLENBURG, S.R.; SCHULTZ, C. L. Cordão Formation: loess deposits in the southern coastal plain of the state of Rio Grande do Sul, Brazil. Anais da Academia Brasileira de Ciências (Online), v. 88, p. 2143-2166, Figura2016.

LORSCHEITTER, M.L. \& DILLENBURG, S.R. Holocene palaeoenvirorments of the northern coastal plain of Rio Grande do Sul, Brazil, reconstructed from palynology of Tramandaí lagoon sediments. Quaternary of South America and Antartic Peninsula, v. 1, p. 39-67, 1998.

MARQUES-TOIGO, M.; MEDEANIC, S.; MOSBRUGGER, V.; ASHRAF, A.R. Palaeo environmental changes in the Maquiné River Valley, RS, Brazil, during the Holocene according to Palynological data. Revista Brasileira de Paleontologia, v. 3, p. 36-47, 2002.

MARTIN, L.; SUGUIO, K.; FLEXOR, J.M. Shell miodens as a source for additional information in Holocene shoreline and sea-level reconstruction: example form the coast of Brazil. In: Sea-level research: a manual for the collection and evaluation of data Ed. by Orson Van de Palassche, v. 18, p. 503-523, 1986

MARTINS, L.R. \& MARTINS I.R. Presença de turfa na plataforma continental do Rio Grande do Sul. Gravel, v. 2, p. 77-85, 2004

MEDEANIC, S. \& DILLENBURG, S.R. The Early Holocene palaeoenvironment history of the Tramandaí Lagoon (RS, Brazil). In: I CONGRESSO DO QUATERNÁRIO DE PAISES DE LÍNGUAS IBÉRICAS, 6, 2001, Lisboa. Anais... Lisboa, 2001, p. 402-405

MEDEANIC, S. The palynomorphs from surface sediments of intertidal marshes in the estuarine part of the Patos Lagoon. Iheringia, Série. Botânica, v. 61, n. 1-2, p. 49-62, 2006.

MEDEANIC, S.; TOLDO Jr., E.E.; DILLENBURG, S.R. Palynological evidence of marine ingression in the Lagoa dos Patos lagoon during the Late Holocene. Revista Universidade de Guarulhos. Geociências, v. 5, p. 141-145, 2000.

MILLIKEN, K.T.; ANDERSON J.B.; RODRIGUEZ A.B. A new composite Holocene sea-level curve for the northern Gulf of Mexico. Special Papers: Geological Society of America, v. 443, p. 1-11, 2008.

NEVES, PCP \& BAUERMANN SG. Feições de uma mata de restinga em Capão do Leão, Planície Costeira Sul, Rio Grande do Sul, Brasil. Pesquisas, v. 51, p. 73-86, 2001.

NEVES, P.C.P. \& LORSCHEITTER, M.L. Palinologia de sedimentos de uma mata tropical paludosa (terra de Areia, Planície Costeira Norte, Rio Grande do Sul, Brasil). Descrições Taxonômicas - Parte II: gimnospermas e angiospermas. Acta Geologica Leopoldensia, v. 18, p. 45-82, 1995.

NEVES, P.C.P. Palinologia de sedimentos Quaternários no Estado do Rio Grande do Sul, Brasil: Guaíba e Capão do Leão. Porto Alegre, 1998. 513 p. Tese (Doutorado), Instituto de Geociências, Universidade Federal do Rio Grande do Sul.

RANDALL, W.P. Decelerating Holocene Sea-Level Rise and its Influence on Southwest Florida Coastal Evolution: A Transgressive/Regressive Stratigraphy. Journal of Sedimentary Petrology, v. 59, n. 6, p. 960-972, 1989.

REIMER, P.J.; MIKE, G.L.; BAILLIE, E.B.; BAYLISS, A.; BECK, J.W.; CHANDA, J.H.; BERTRAND, P.G.B.; BUCK, C.E.; GEORGE, S,B.; CUTLER, K,B.; DAMON, P.E.; LAWRENCE, E.R, RICHARD, G.; FAIRBANKS, F.M.; GUILDERSON, T.P.; HOGG, A.G.; KONRAD; A;H; KROMER, B. MCCORMAC, G.; MANNING, S.; RAMSEY, H.B.; REIMER, R.W.; REMMELE, S.; SOUTHON, J.R.; STUIVER, M.; TALAMO, S.; TAYLOR, F.W.; VAN DER

São Paulo, UNESP, Geociências, v. 39, n. 2, p. 393 - 410, 2020 409 
PLICHT, J.; WEYHENMEYER, C.E. Intcal04 Terrestrial RAdiocarbon Age Calibration, 0-26 Cal KYR BP. RADIOCARBON, v 46, n 3, p 1029-1058. 2004.

RITTENHOUSE, G. A visual method of estimating two dimensional sphericity. Journal of Sedimentary Petrology, v. 13, n. 2, p. 79-81, 1943.

ROY P.S.; COWELL P.J.; FERLAND M.A.; THOM B.G. Wave Dominated Coasts. In: CARTER R.W.G. \& WOODROFFE CD (Ed.), Coastal Evolution, Late Quaternary Shoreline Morphodynamics, Cambridge: Cambridge University Press, p. 121-186, 1994.

SAMUELSBERG, T.J. \& PICKARD N.A.H. Upper Carboniferous to Lower Permian transgressive-regressive sequences of central Spitsbergen, Arctic Norway, Geological Journal, v. 34, p. 393-411, 1999.

SWIFT, D.J.P. \& THORNE, J.A. Sedimentation on Continental Margins, I - a general model for shelf sedimentation. Special Publication of the International Association of Sedimentologists, v. 14, p. 3-31, 1991.

SWIFT, D.J.P. Continental shelf sedimentation. In: Stanley, D., Swift, D.J.P. (Eds.), Marine Sediment Transport and Environmental Management. John Wiley \& Sons, New York, p. 311-350, 1976.

TALMA, A.S. \& VOGEL, J.C. A Simplified Approach to the Calibration of Radiocarbon Dates. Radiocarbon, v. 35, n. 2, p. 317-322, 1993.

TOMAZELLI, L.J. \& DILLENBURG, S.R. O uso do registro geológico e geomorfológico na avaliação da erosão de longo prazo na costa do Rio Grande do Sul. Geosul, v. 14, n. 27, p. 47-53, 1998.

TOMAZELLI, L.J. \& VILLWOCK, J.A. Geologia do Sistema Lagunar Holocênico do Litoral Norte do Rio Grande do Sul. Pesquisas, v. 18, p. 13-24, 1991.

TOMAZELLI, L.J. \& VILLWOCK, J.A. Processos Erosivos na Costa do Rio Grande do Sul, Brasil: Evidências de uma Provável Tendência Contemporânea de Elevação do Nível Relativo do Mar. In: CONGRESSO DA ASSOCIAÇÃO BRASILEIRA DE ESTUDOS DO QUATERNÁRIO, 2, 1989 , Rio de Janeiro, Anais...Rio de Janeiro: Sociedade Brasileira de Geologia, 1989, p. 16.

TOMAZELLI, L.J. Contribuição ao estudo dos sistemas deposicionais holocênicos do nordeste da Província Costeira do Rio Grande do Sul. Com ênfase no sistema eólico. Porto Alegre, 1990. 270 p. Tese (Doutorado), Instituto de Geociências, Universidade Federal do Rio Grande do Sul.

TOMAZELLI, L.J. e VILLWOCK, J.A. O Cenozoico no Rio Grande do Sul: Geologia da Planície Costeira. In: HOLZ, M.\& DE ROS, L.F. (Eds) Geologia do Rio Grande do Sul. Ed. CIGO/UFRGS, Porto Alegre. p. 375-406, 2000.
TOMAZELLI, L.J.; VILLWOCK, J.A.; DILLENBURG, S.R.; BACHI, F.A.; DEHNARDT, B.A. Significance of present-day coastal erosion and marine transgression, Rio Grande do Sul, Southern Brazil. Anais da Academia Brasileira de Ciências, v. 70, n. 2, p. 221-229, 1998.

TOMAZELLI, L.J.; VILLWOCK, J.A.; BARBOZA, E.G.; BUCHMANN, F.S.C. \& SANTOS, L.A.O. 1999. A erosão costeira no Rio Grande do Sul: Uma avaliação das causas e consequências. In: CONGRESSO DA ASSOCIAÇÃO BRASILEIRO DE ESTUDOS DO QUATERNÁRIO, 7, 1999, Porto Seguro, Anais... Porto Alegre: Sociedade Brasileira de Geologia

TÖRNQVIST T.E., BICK S.J.; GONZÁLEZ J.L. Tracking the sea-level signature of the 8.2 ka cooling event: New constraints from the Mississippi Delta. Geophysical Research Letters, v. 31, p. 1-4, 2004.

TRAVERSE, A. \& GINSBURG, R.N. Pollen and associated microfossils in the marine surface sediments of the Great Bagama bank. Review of Palaeobotany and Palynology v. 3, p. 243-254, 1967.

VAN WAGONER, J.C.; MITCHUM, R.M.; CAMPION, K.M. \& RAHMANIAN, V.D. Siliciclastic Sequence Stratigraphy In Well Logs, Cores And Outcrops: Cencepts For HighResolution Correlation Of Time And Facies. American Association of Petroleum Geologists Methods In Exploration Series, v. 7, 55 p. 1991.

VICTORIA, R.L.; FERNANDES, F.; MARTINELLI, L.A.; PICCOLO, M.C.; CAMARGO, P.B.; TRUMBORE, S. Past vegetation changes in the Brazilian Pantanal arboreal-grass Savanna ecotone by using carbon isotopes in the soil organic matter. Global Change Biology, v. 1, p. 101-108, 1995.

VILLWOCK, J.A. Geology of the Coastal Province of Rio Grande do Sul, Southern Brazil. A Synthesis. Pesquisas, v. 16, p. 5-49, 1984.

WETZEL, R.G. Limnology, W.B. Sauders College Publishing, Philadelphia, 743 p., 1975

ZENCOVITCH, V.P. On the genesis of cuspate spits along lagoon shores. Journal of Geology, v. 67, p. 267-277,1959.

Submetido em 11 de setembro de 2019 Aceito para publicação em 17 de abril de 2020 